\title{
LAS PIPAS DEL SALAR DE ATACAMA: REEVALUANDO SU ORIGEN Y USO
}

\author{
Francisca Gili' ${ }^{1}$, Javier Echeverría ${ }^{2}$, Emily Stovel ${ }^{3}$, Michael Deibel ${ }^{4}$ \\ y Hermann M. Niemeyer ${ }^{5}$
}

\begin{abstract}
Resumen
Este artículo presenta un catastro de las pipas cerámicas provenientes de sitios arqueológicos del salar de Atacama (SA) y describe sus atributos morfológicos, la composición química elemental de las pastas y la composición química de sus residuos de combustión. Las pipas presentan una forma distintiva del SA: la boquilla con labio evertido y el hornillo con motivos zoo-antropomorfos abstractos. Las pastas presentan atributos de origen local y sus residuos ausencia de triptaminas y nicotina en niveles traza, sumado a una variedad de compuestos genéricos de origen vegetal y animal. Estos atributos sugieren una finalidad distinta del consumo de compuestos psicotrópicos y permite hipotetizar que las pipas del SA fueron utilizadas para sahumar. Los resultados se comparan exploratoriamente con aquellos publicados sobre pipas del Noroeste de Argentina.
\end{abstract}

Palabras claves: Pipas cerámicas - alucinógenos - sahumerio - análisis de residuos - análisis de pastas. This article provides a survey of ceramic pipes from archaeological sites near the salar de Atacama and describes their morphological attributes, paste elemental composition and combustion residue composition. Pipes exhibit a shape distinctive of the SA: pipe stems with everted lips and bowls with abstract zoo- or anthropomorphic motifs. The pastes present attributes of local origin and the residues lack of tryptamines and traces of nicotine and a variety of generic compounds of plant and animal origin. These results suggest that consumption of hallucinogens was not the primary use of the pipes; this allows hypothesizing that they may have been used as incense burners. An exploratory comparison of the results with those of pipes from Northwestern Argentina is presented.

Keywords: Ceramic pipes - hallucinogens - incense burners - residue analysis - paste analysis.

Recibido: septiembre 2015. Aceptado: octubre 2016.

\section{* InTRoducción}

Las pipas de tiempos prehispánicos en el área del SA por lo general se han vinculado a la costumbre de consumir sustancias psicotrópicas. Esta actividad está ampliamente documentada entre los pueblos americanos tanto del pasado (Schultes 1998) como del presente (Furst 1990 [1972]). Los métodos de consumo, los objetos utilizados y las sustancias consumidas muestran una gran diversidad tanto espacial como temporal. En América, los métodos más difundidos han sido la masticación de sustancias vegetales, la inhalación nasal de polvos mediante tubos y tabletas, la ingesta de bebidas fermentadas en diversos tipos de vasijas, la incorporación de sustancias a través de enemas y la aspiración de humo a través de pipas (de Smet 1985).

En Chile, el registro arqueológico muestra un vasto y variado conjunto de tabletas de inhalación en sitios del Norte Grande (Torres 1987, 1998-1999), particularmen-

1 Investigador Independiente, Eliodoro Yáñez 922 dpto. 53, Santiago, CHILE. Email: franciscagili@gmail.com

2 Facultad de Ciencias, Universidad de Chile. Casilla 653, Santiago, CHILE, Email: echeverria@abulafia.ciencias.uchile.cl; Facultad de Química y Biología, Universidad de Santiago de Chile, Casilla 40, Correo 33, Santiago, CHILE. Email: javier.echeverriam@ usach.cl

3 Site Manager, Casa San Ysidro: the Gutiérrez/Minge House, Albuquerque Museum, Albuquerque, NM, USA. Email: estovel@ cabq.gov; Instituto de Investigación Arqueología y Museo Gustavo Le Paige. Calle Le Paige 380, San Pedro de Atacama, CHILE. Email: estovel@ucn.cl

4 Department of Chemistry, Earlham College, Richmond, IN, USA. Email: deibemi@earlham.edu

5 Facultad de Ciencias, Universidad de Chile, Casilla 653, Santiago, CHILE.Email: niemeyer@abulafia.ciencias.uchile.cl) 
te en el área del SA y su aparición excepcional en el Norte Semiárido (Albornoz 2015); recipientes posiblemente utilizados para la preparación e ingesta de bebidas fermentadas a lo largo del país (Pardo y Pizarro, 2005); tubos acoplados a vejigas de animales utilizados como dosificadores, gotarios o enemas en la zona de Arica y SA (Berenguer y Acevedo 2015; Mostny 1952 ); y pipas, que muestran una distribución espacial y temporal amplia (Westfall 1993-1994).

A lo largo del litoral desértico de Chile, solo aparecen pipas desde Antofagasta hacia el sur (Mostny 1964); son pipas líticas del tipo $\mathrm{T}$ invertida con un tubo abierto $\mathrm{y}$ el otro sellado, muy probablemente provenientes de intercambios (Ballester y Gallardo 2011; Latcham 1909) con pueblos asociados al Complejo El Molle (ca. o-80o DC) que habitaban los valles de los ríos Copiapó y Elqui (Cornely 1956; Latcham 1940; Niemeyer et al. 1989; Westfall 1993-1994). Hacia el sur de estos ríos, se produce una transición a las pipas líticas del tipo T-invertida con ambos tubos abiertos y monitor, de material cerámico (Planella et al. 2016a, b) en sitios de la zona central y centro-sur asociados a las culturas Bato (150 AC-900 DC) y Llolleo (100 AA-1300 DC) (Niemeyer et al. 1989, 1998; Planella et al. 2000; Falabella et al. 2001; Westfall 1993-94; Reyes et al. 2003-2004) y Complejo Pitrén (500-1400 DC) (Gordon 1985; Aldunate 1989; Quiroz y Sánchez 2005; Belmar et al. 2016).

Respecto del área de la circumpuna occidental existen menciones acerca de la presencia de pipas en el sector del río Salado en estructuras arquitectónicas asociadas al Período Formativo Tardío en la aldea de Turi (500-700 DC) (Adán y Urbina 2007; Castro et al. 1984). A lo largo del río Loa destacan fragmentos de pipas cerámicas provenientes de la zona delimitada entre el Alto Loa y el río Salado (Aldunate et al. 1986) y asociadas a fragmentos cerámicos del estilo Vaquerías (estilo cerámico del Noroeste de Argentina -NOA, últimos siglos AC- siglo IV DC: Bugliani y Pereyra-Domingorena 2012); fragmentos de pipas acodadas de cerámica en el cementerio de Topater (Thomas et al. 1989-1990, 1995), que en términos formales son similares a las descritas para Campo Colorado en el NOA (Gili 2014) cuyo contexto presenta datación radiocarbónica: $100 \pm 70$ DC (Tarragó 1996); un fragmento de pipa de forma tubular que aparentemente sería de origen lítico en San Salvador en el curso medio del río Loa asignado al
Período Formativo Medio (Torres-Rouff et al. 2012); ${ }^{6}$ una pipa lítica acodada con una representación grabada encontrada en Quillagua (com. pers. Carolina Agüero 2014); y un fragmento del hornillo de una pipa de cerámica acodada con una representación volumétrica de un camélido con restos de pigmento en superficie en Calate en la sección inferior del río Loa, cuyo contexto arrojó un fechado radiocarbónico para el Formativo Tardío entre 200 y 400 DC. (Torres-Rouff et al. 2012).

Los registros arqueológicos en el NOA (Figura 1) muestran la utilización de pipas a partir del Período Arcaico Tardío. En efecto, las pipas más antiguas del continente americano, confeccionadas en hueso, aparecen en el sitio Inca Cueva y tienen aproximadamente 4.000 años de antigüedad, en tanto las pipas de piedra aparecen en el sitio Huachichocana y tienen aproximadamente 3.000 años de antigüedad (Aguerre et al. 1973; Fernández Distel 1980; Aschero y Yacobaccio 1998-1999). La tradición de fumar integró posteriormente el uso de la cerámica en la elaboración de artefactos para desarrollar esta práctica. Las pipas cerámicas más tempranas para la zona del NOA se han registrado en el sector de las selvas orientales, específicamente en el valle de San Francisco, con una antigüedad de 2.600 años (Fernández et al. 1999). La tradición de fumar en pipa perduró en los sectores valliserranos del NOA hasta 1000-1100 DC (Pazzarelli 2011).

Respecto del uso de estos artefactos, diversas investigaciones en pipas han corroborado la utilización de Anadenanthera sp. y Nicotiana sp. a partir de referencias etnográficas (Serrano 1934; Wilbert 1987; Pérez Gollán y Gordillo 1994) y de estudios de residuos en piezas arqueológicas (Fernández Distel 1980; Elfernik 1983; Capparelli et al. 2006; Rosso y Spano 2005-2006; Bugliani et al. 2010; Gili et al. 2009; Gili y Villagrán 2011; Martin 2012; Carrasco et al. 2015; Torres 2001; Torres et al. 1991; Torres y Repke 2006).

La mayor parte de las publicaciones que dentro de sus temáticas han abordado las pipas en el SA se refieren

\footnotetext{
6 Aunque fue reportada como de cerámica negra pulida (Torres Rouff et al. 2012), el análisis de pasta posterior indica que correspondería a algún tipo de piedra finamente labrada (com. pers. Itací Correa 2012).
} 
a sus cualidades formales, estilísticas y tipológicas y a su probable proveniencia (p.e., Tarragó 1989; Westfall 1993-1994; Torres 1998-1999; Llagostera 2001, 2015). Diversos autores han postulado que las pipas encontradas en la cuenca del SA corresponden a bienes foráneos debido a que presentan ciertas semejanzas morfológicas y estilísticas con aquellas elaboradas en cerámica durante el Período Formativo en el NOA. Tarragó (1989) asocia su procedencia específicamente al sector de La Poma (norte del valle Calchaquí, Provincia de Salta), en tanto Westfall (1993-1994: 124) las relaciona con las culturas Tafí y Condorhuasi que se desarrollan un poco más al sur del sector atribuido por Tarragó, específicamente en los valles del Hualfín y Tafí. Por su parte, Torres (1998-1999:
53-54) señala que ciertas pipas cerámicas encontradas en el SA son muy similares a las del estilo San Francisco, y Llagostera (2001: 104) indica, para el caso específico de las pipas acodadas de San Pedro de Atacama (SPA), que su naturaleza heterogénea no solo obedece al hecho de ser foráneas, sino también a que provienen de áreas diferentes. Estos estudios han enfatizado entonces que las pipas encontradas en el SA han sido confeccionadas fuera de esta área y que su presencia en el salar es un indicador de un bien foráneo, como lo recalca recientemente Llagostera (2015).

Desde una perspectiva más amplia, los estudios de diversas materialidades en SPA han mostrado que para las

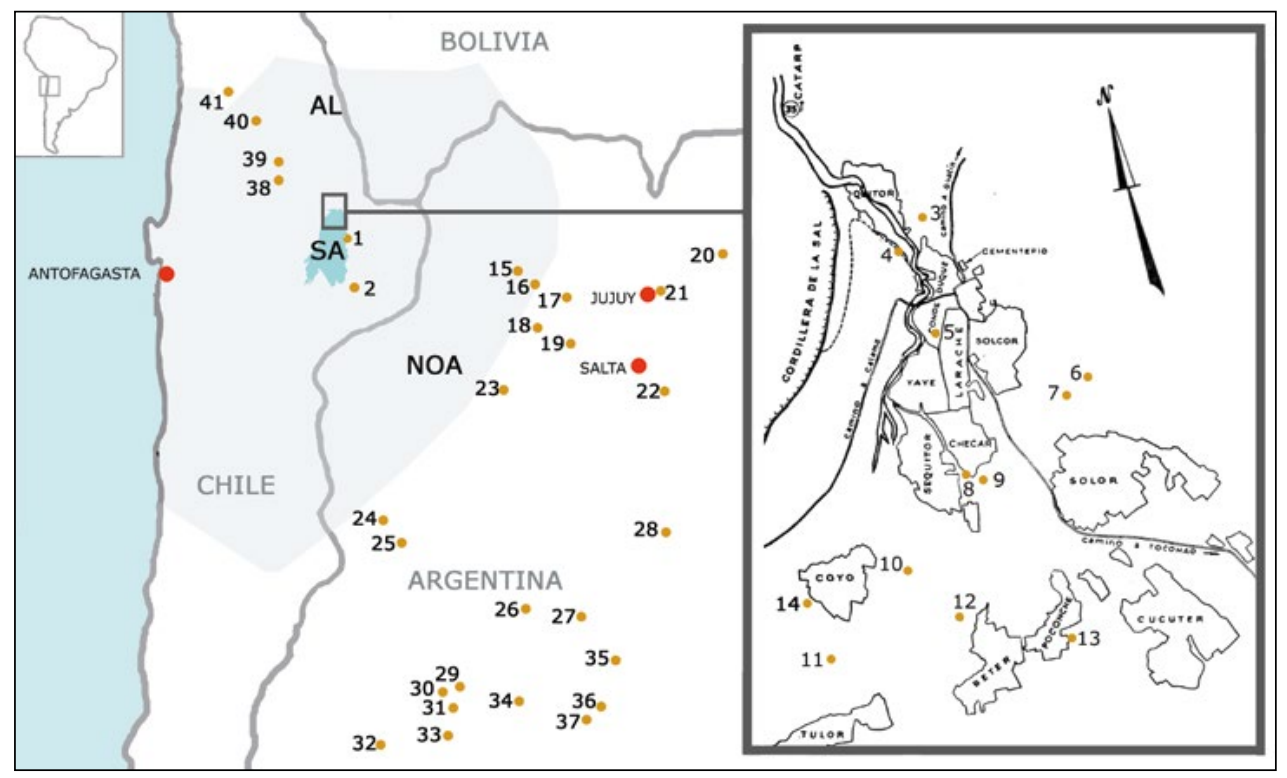

Figura 1. Mapa general del área circumpuneña occidental y del Noroeste de Argentina, y detalles de San Pedro de Atacama. Se indican los sitios arqueológicos donde se han encontrado pipas y otros lugares nombrados en el texto. 1/Toconao-Toconao Oriental (Le Paige 1955-1975); 2/Tulán 54 (Núñez et al. 2007); 3/Quitor 5 (Le Paige 1955-1975); 4/Quitor 6 (Le Paige 1955-1975); 5/Larache (Le Paige 19551975); 6/Solor 4 (Le Paige 1955-1975); 7/Solor 3 (Le Paige 1955-1975); 8/Sequitor Alambrado Acequia (Le Paige 1955-1975); 9/Sequitor Alambrado Oriental (Le Paige 1955-1975); 10/Tchapuchayna (Le Paige 1955-1975); 11/Tulor Algarrobo (Le Paige 1955-1975); 12/Beter (Le Paige 1955-1975); 13/Poconche (Le Paige 1955-1975); 14/Coyo Aldea (Graffam 1995); 15/Inca Cueva (Fernández Distel 1980); 16/Huachichocana (Fernández Distel 1980); 17/Las Cuevas (Fernández et al. 1999); 18/La Quebrada Estancia Grande (Fernández et al. 1999); 19/Cerro el Dique (Fernández et al. 1999); 20/San Francisco (Fernández et al. 1999); 21/Palpalá (Fernández et al. 1999); 22/El Piquete (Dougherty 1972); 23/Campo Colorado (Gollán y Gordillo 1993); 24/Tebenquinche (Bugliani et al. 2010); 25/Laguna Blanca (Bugliani et al. 2010); 26/El Cardonal (Bugliani et al. 2010); 27/Masao (Fernández et al. 1999); 28/La Candelaria (Pérez Gollán 1994); 29/La Aguada (Fernández et al. 1999); 30/Condorhuasi (Fernández et al. 1999); 31/La Ciénaga (Fernández et al. 1999); 32/Saujil (Fernández et al. 1999); 33/Belén (Fernández et al. 1999); 34/Alamito (Fernández et al. 1999); 35/Tafí (Fernández et al. 1999); 36/El Rodeo Grande (Fernández et al. 1999); 37/Tuscamayo Poman (Fernández et al. 1999); 38/Topater (Thomas et al. 1989/1990, 1995); 39/San Salvador (Torres Rouff et al. 2012); 40/Quillagua (com. pers. Aguëro 2014); 41/Calate (Torres-Rouff et al. 2012).*

* Las ubicaciones de los sitios del NOA son aproximadas y fueron definidas con la colaboración de la Dra. Verónica Williams. 
culturas que se evidencian en la arqueología de la zona, fue determinante la influencia de costumbres, procesos, objetos o materias primas foráneas que son reinterpretados, adaptados, rediseñados o utilizados, respectivamente, para llegar a costumbres y objetos de tradición local (Salazar et al. 2014). Así, por ejemplo, se encuentran en SPA tabletas de inhalación con estilo foráneo (Niemeyer et al. 2015) pero también se producen tabletas con estilo local (Horta 2014), se importan colorantes o fibras teñidas utilizados para fabricar textiles de estilo local (Niemeyer y Agüero 2015), se importan maderas que son incorporadas en tabletas de inhalación de estilo local (Niemeyer 2013; Niemeyer et al. 2013; Riquelme-Toro y Niemeyer 2015).

Estos antecedentes permiten hipotetizar que las pipas encontradas en SPA podrían no ser de origen foráneo sino corresponder a una adaptación local. Este trabajo describe un estudio multidisciplinario de las pipas del SA, que de forma exploratoria aborda un análisis comparativo de ellas con pipas del NOA en cuanto a sus cualidades morfológicas, análisis de las sustancias consumidas en ellas y análisis de la naturaleza de las pastas cerámicas utilizadas en su manufactura. El estudio comprende el catastro de las pipas preservadas por el Museo R.P. Gustavo Le Paige de la Universidad Católica del Norte (IIAM).

\section{* Materiales y métodos}

Las pipas del SA preservadas por el IIAM (Tabla 1) fueron recolectadas principalmente por Gustavo Le Paige entre las décadas de 1950 y 1970. A pesar de carecer de las metodologías de excavación arqueológica actualmente en uso, se trató de excavaciones sistemáticas con un exhaustivo registro de los contextos. Los sitios excavados por Le Paige son principalmente funerarios, con restos humanos vinculados a los ajuares con los que fueron depositados. Tras las investigaciones de Le Paige, varios investigadores del IIAM continuaron estudios en el área y contribuyeron a la conformación de lo que es actualmente la colección.

Se realizó una búsqueda exhaustiva en los depósitos del IIAM para identificar las pipas existentes en ellos. Posteriormente se examinaron los datos de registro de los materiales en las notas de campo de Le Paige (1955-1975) y también datos de excavaciones posteriores que reali- zaron otros investigadores (Graffam 1995, Nuñez et al. 2007). Esto permitió definir, en la mayor parte de los casos, los sitios donde fueron encontradas las pipas y los otros artefactos y restos bioantropológicos a los que estaban vinculadas. De modo paralelo se revisó la literatura sobre pipas que se han encontrado en sitios del NOA, se recopilaron datos cronológicos y se definieron de modo exploratorio grupos diagnósticos que permitieron ver diferencias y similitudes morfológicas con las pipas del SA.

Los estudios para conocer la composición elemental de las pastas utilizadas en la pipas se realizaron mediante fluorescencia de rayos X (FRX). Hay debate en la literatura arqueológica sobre la confiabilidad de la pistola portátil de FRX (Shackley 2011; Goodale et al. 2012; Speakman y Shackley 2013; Johnson 2014; Hunt y Speakman 2015). Respecto de dichos antecedentes, en el presente estudio no se incluyeron los elementos pocos confiables. El análisis cuantitativo utilizado comparó los perfiles de las pipas con los de vasijas mortuorias o domésticas según los cinco elementos más diagnósticos para la zona ( $\mathrm{Ti}, \mathrm{Fe}$, $\mathrm{Zr}, \mathrm{Rb}$, Sr; para no utilizar todos los elementos disponibles según Baxter y Jackson 2001) y se transformaron los datos a valores $\log \left({ }^{(10}\right)$ porque las cantidades absolutas de los elementos seleccionados difieren mucho (véase Baxter 1995). Hemos empleado el instrumento portátil de forma exploratoria y consideramos los datos químicos como "índices relativos" en vez de valores absolutos. Con esto queremos decir que nuestros resultados sirven como medidas de comparación química relativa que nos permiten evaluar diferencias (o similitudes) químicas entre grupos de objetos, y la presencia en este caso de pipas de posible manufactura local y otras posiblemente no-locales, sin poder determinar claramente el lugar de manufactura.

El perfil "local" se ha definido en comparación con perfiles de objetos cerámicos locales encontrados en contextos funerarios y domésticos (Stovel et al. 2013). Los perfiles químicos de las pipas se definieron utilizando promedios de tipos que se fabricaron en las comunidades de SPA y el Alto Loa entre el Formativo Tardío y el Intermedio Tardío. Los ejemplares utilizados en el cálculo de promedios fueron encontrados en tumbas o contextos domésticos de SPA o del Alto Loa. Los promedios representan valores para cada comunidad para cada período. La producción cerámica de SPA, cambia muy poco durante el curso de la prehistoria y es posible que las recetas elaboradas al 
principio del desarrollo de la tecnología fueran usadas por más de mil años. Cualquier objeto con un perfil que no se agrupa con valores locales se entiende como producto de una receta diferente o de posible origen no-local. El grupo Dupont del Alto Loa es un promedio de valores para vasijas tipo que datan del final del Período Medio y van hasta mediados del Intermedio Tardío (Uribe 2002); provienen de contextos arqueológicos domésticos del sito del Pucara de Turi (Aldunate 1991; Varela et al. 1991). Los promedios de valores para los tipos Dupont y Aiquina (es decir, SPA y el Loa Superior) vienen de un estudio reciente de la cerámica del Intermedio Tardío (Stovel et al. 2013). El grupo Negro Pulido de SPA corresponde a un promedio de valores para 74 vasijas que datan de los Períodos Formativo Tardío y Medio (Stovel 2013). El grupo funerario presenta un promedio de 150 muestras analizadas de tumbas locales de SPA. Se incluyó también un promedio de tres muestras de cerámica moderna hecha a mano con arcilla rescatada de un lugar próximo al río San Pedro al norte de SPA. Se analizaron estas muestras para explorar las posibilidades de distintas recetas y períodos de producción que son definidos por los perfiles cerámicos detectados con FRX portátil.

La identificación de estos grupos químicos pasó por un análisis de componentes principales, tal como se encuentra en Frankel y Webb (2012) y Tykot et al. (2013). Un análisis de componentes principales permite identificar combinaciones de variables que definen grupos en la muestra bajo estudio y se expresa el poder de esas combinaciones en un porcentaje de variación capturada. Los estudios previos citados y el nuestro demuestran que aunque la exactitud puede fallar en ciertos contextos, la pistola portátil de FRX ha podido confirmar conjuntos de relevancia arqueológica que corroboran agrupamientos identificados con otros métodos tales como el análisis por activación neutrónica (AAN). Los datos que se presentarán fueron comparados con vasijas analizadas con la misma metodología y el mismo instrumento de sitios de la cuenca del SA y zonas aledañas en un amplio rango de tiempo (p.e. Stovel et al. 2013). El análisis utilizó una pistola portátil de FRX (Olympus INNOV X Alpha 4500) con una lectura de dos minutos en el módulo LEAP (Light Element Analysis Protocol) y dos minutos en el módulo estándar.

El análisis químico de los residuos presentes en las pipas se realizó por cromatografía de gases acoplada a espectrome- tría de masas (CG-EM). Se analizaron los 25 artefactos (pipas completas y fragmentos aislados) que en una inspección visual mostraron residuos ya sea en los hornillos, en los tubos o en ambos. Los residuos fueron extraídos mediante el raspado de la superficie interna carbonizada del artefacto con un instrumento metálico previamente sanitizado con alcohol isopropílico (Planella et al. 2012). Para su análisis, estos residuos fueron sometidos a extracción sólido-líquido, siguiendo el protocolo de Echeverría et al. (2014) que conduce a extractos clorofórmicos y metanólicos. La técnica de CG-EM fue aplicada en dos modalidades: i) barrido completo de iones (BCI), que monitorea todos los iones de la muestra en una ventana entre $\mathrm{m} / \mathrm{z} 50$ y 500 y que produce espectros de masas que pueden ser comparados con una base de datos y con la información disponible en literatura para su identificación, pero que presenta la desventaja de ser poco sensible (alto límite de detección); y ii) monitoreo selectivo de iones (MSI), que detecta uno o más iones específicos de uno o más compuestos previamente seleccionados, lo que mejora ostensiblemente los límites de detección. Tomando en consideración estos resultados, el análisis por MSI fue orientado hacia la búsqueda de alcaloides provenientes de los géneros Nicotiana y Anadenanthera.

\section{$*$ Resultados}

\section{Inventario de pipas en el salar de Atacama}

Se estableció la existencia de un total de 64 pipas en la colección del IIAM provenientes del SA, 26 de ellas con un alto nivel de integridad (Figura 2) y 38 correspondientes a fragmentos (Figura 3). En relación al hallazgo de los vínculos contextuales mediante las notas de Le Paige, en un $97 \%$ de los casos se pudieron asociar las pipas a sitos y/o contexto de procedencia (Figura 4). Las pipas referenciadas se encontraron en sitios distribuidos en toda la

7 Hay cuatro casos que no aparecen en las figuras por no encontrarse accesibles para fotografías. Una es del sitio Larache y es pequeña y de piedra con una forma distinta a la diagnóstica del SA. Otra es de cerámica del sitio Toconao Oriente tumba 4317 y se encuentra en préstamo en el sitio de Tulor. Hay otra pipa publicada por Llagostera (2001) del sitio Toconao Oriente tumba 4635 que no se encontró en la revisión de la colección. Por último, hay fragmentos de pipas encontrados en el sitio Tulan 54 (Núñez et al. 2007), que se encuentra albergados en el IIAM pero no fue posible acceder a ellos para su registro. 
Francisca Gili, Javier Echeverría, Emily Stovel, Michael Deibel y Hermann M. Niemeyer

\begin{tabular}{|c|c|c|c|c|c|c|c|}
\hline Figura & Sitio & Contexto & Inventario IIAM & Estado & Materialidad & $\begin{array}{l}\text { Análisis } \\
\text { FRX }\end{array}$ & $\begin{array}{c}\text { Análisis de } \\
\text { CG-EM }\end{array}$ \\
\hline $2.1 \mathrm{~A}$ & Quitor 6 & tumba $2522-2523$ & 18877 & $\mathrm{BN}$ & $\mathrm{C}$ & GA, n`16 & $\mathrm{SN}$ \\
\hline $2.1 \mathrm{~B}$ & Quitor 6 & tumba $2639-2640$ & 18879 & $\mathrm{BN}$ & $\mathrm{C}$ & $\mathrm{GC}, \mathrm{n}^{\circ} 17$ & SN \\
\hline $2.1 \mathrm{C}$ & Quitor 6 & tumba 2796-2799 & 7284 & $\mathrm{BN}$ & C & $\mathrm{GC}, \mathrm{n}^{\circ} 19$ & $\mathrm{CN}$ \\
\hline $2.1 \mathrm{D}$ & Quitor 5 & tumba 1947 & 18763 & $\mathrm{BN}$ & $\mathrm{C}$ & $\mathrm{GA}, \mathrm{n}^{\circ} 20$ & $\mathrm{CN}$ \\
\hline $2.2 \mathrm{~A}$ & Sequitor Alambrado & probable asociación a tumba 1081 & 7230 & BN & $\mathrm{C}$ & $\mathrm{GA}, \mathrm{n}^{\circ} 8$ & SN \\
\hline $2.2 \mathrm{~B}$ & Sequitor Alambrado & tumba 947 & 7231 & $\mathrm{BN}$ & $\mathrm{C}$ & $\mathrm{GA}, \mathrm{n}^{\circ} 11$ & \\
\hline $2.2 \mathrm{C}$ & Sequitor & sin datos de tumba & 14160 & $\mathrm{BN}$ & $\mathrm{C}$ & & $\mathrm{CN}$ \\
\hline $2.2 \mathrm{D}$ & $\begin{array}{c}\text { Sequitor Alambrado } \\
\text { Oriental }\end{array}$ & tumba 1627 & $\begin{array}{l}\text { Sin número de } \\
\text { registro }\end{array}$ & $\mathrm{BN}$ & $\mathrm{C}$ & $\mathrm{GC}, \mathrm{n}^{\circ} 13$ & \\
\hline $2.2 \mathrm{E}$ & $\begin{array}{c}\text { Sequitor Alambrado } \\
\text { Acequia }\end{array}$ & $\begin{array}{l}\text { sin vinculación a contexto } \\
\text { mortuorio }\end{array}$ & 17106 & $\mathrm{BN}$ & $\mathrm{C}$ & $\mathrm{GA}, \mathrm{n}^{\circ} 47$ & $\mathrm{CN}$ \\
\hline $2.2 \mathrm{~F}$ & Sequitor & tumba $1060-1068$ & $\begin{array}{l}\text { Sin número de } \\
\text { registro }\end{array}$ & $\mathrm{BN}$ & $\mathrm{C}$ & $\mathrm{GA}, \mathrm{n}^{\circ} 15$ & \\
\hline $2.2 \mathrm{G}$ & $\begin{array}{c}\text { Sequitor Alambrado } \\
\text { Acequia }\end{array}$ & $\begin{array}{l}\text { sin vinculación a contexto } \\
\text { mortuorio }\end{array}$ & 7772 & $\mathrm{BN}$ & $\mathrm{C}$ & $\mathrm{GC}, \mathrm{n}^{\circ} 14$ & $\mathrm{SN}$ \\
\hline $2.2 \mathrm{H}$ & $\begin{array}{c}\text { Sequitor Alambrado } \\
\text { Acequia }\end{array}$ & $\begin{array}{l}\text { sin vinculación a contexto } \\
\text { mortuorio }\end{array}$ & $\begin{array}{l}\text { Sin número de } \\
\text { registro }\end{array}$ & $\mathrm{BN}$ & $\mathrm{C}$ & $\mathrm{GC}, \mathrm{n}^{\circ} 10$ & \\
\hline $2.2 \mathrm{I}$ & $\begin{array}{c}\text { Sequitor Alambrado } \\
\text { Oriental }\end{array}$ & tumba $1075-1080$ & 7232 & $\mathrm{BN}$ & $\mathrm{C}$ & $\mathrm{GA}, \mathrm{n}^{\circ} 9$ & \\
\hline $2.3 \mathrm{~A}$ & Toconao Oriente & tumba 4263 & 4263 & $\mathrm{BN}$ & $\mathrm{C}$ & $\mathrm{GC}, \mathrm{n}^{\circ} 2$ & \\
\hline $2.3 \mathrm{~B}$ & Toconao Oriente & tumba $4203-4205$ & 7306 & $\mathrm{BN}$ & $\mathrm{C}$ & $\mathrm{GC}, \mathrm{n}^{\circ} 1$ & SN \\
\hline $2.3 \mathrm{C}$ & Toconao Oriente & tumba $4646-4748$ & $\begin{array}{l}\text { Sin número de } \\
\text { registro }\end{array}$ & $\mathrm{BN}$ & $\mathrm{C}$ & GA, n' 6 & $\mathrm{CN}$ \\
\hline $2.3 \mathrm{D}$ & Toconao Oriente & tumba 4383 & $\begin{array}{l}\text { Sin número de } \\
\text { registro }\end{array}$ & $\mathrm{BN}$ & $\mathrm{C}$ & $\mathrm{GC}, \mathrm{n}^{\circ} 5$ & $\mathrm{CN}$ \\
\hline $2.3 \mathrm{E}$ & Toconao Oriente & tumba $4708-4709$ & 7311 & $\mathrm{BN}$ & $\mathrm{C}$ & $\mathrm{GA}, \mathrm{n}^{\circ} 7$ & SN \\
\hline $2.4 \mathrm{~A}$ & Solor 3 & tumba 951 & $\begin{array}{l}\text { Sin número de } \\
\text { registro }\end{array}$ & $\mathrm{BN}$ & $\mathrm{C}$ & $\mathrm{GC}, \mathrm{n}^{\circ} 21$ & $\mathrm{CN}$ \\
\hline $2.4 \mathrm{~B}$ & Tchapuchayna & tumba 3821 & 17105 & $\mathrm{BN}$ & $\mathrm{C}$ & $G A, n^{\circ} 29$ & $\mathrm{CN}$ \\
\hline $2.4 \mathrm{C}$ & Larache & $\begin{array}{l}\text { sin asociación clara aun contexto } \\
\text { funerario }\end{array}$ & $\begin{array}{l}\text { Sin número de } \\
\text { registro }\end{array}$ & $\mathrm{BN}$ & $\mathrm{C}$ & $\mathrm{GA}, \mathrm{N}^{\circ} 35$ & $\mathrm{CN}$ \\
\hline $2.4 \mathrm{D}$ & Larache & tumba 1715 & $\begin{array}{l}\text { Sin número de } \\
\text { registro }\end{array}$ & $\mathrm{BN}$ & $\mathrm{C}$ & $\mathrm{GC}, \mathrm{n}^{\circ} 36$ & $\mathrm{CN}$ \\
\hline $2.4 \mathrm{E}$ & sin datos de contexto & sin datos de tumba & $\begin{array}{l}\text { Sin número de } \\
\text { registro }\end{array}$ & $\mathrm{BN}$ & $\mathrm{C}$ & $\mathrm{GC}, \mathrm{n}^{\circ} 48$ & $\mathrm{CN}$ \\
\hline $3 \mathrm{~A}$ & Toconao Oriente & tumba $4380-4381$ & 7307 & $\mathrm{~F}$ & $\mathrm{C}$ & & \\
\hline $3 \mathrm{~B}$ & Toconao Oriente & tumba 4372 & 7310 & F & $\mathrm{C}$ & & $\mathrm{SN}$ \\
\hline $3 \mathrm{C}$ & $\begin{array}{c}\text { Sequitor Alambrado } \\
\text { Oriental }\end{array}$ & tumba $1052-1059$ & $\begin{array}{l}\text { Sin número de } \\
\text { registro }\end{array}$ & $\mathrm{F}$ & $\mathrm{C}$ & & \\
\hline $3 \mathrm{D}$ & Tchapuchayna & túmulo 21 & $\begin{array}{l}\text { Sin número de } \\
\text { registro }\end{array}$ & $\mathrm{F}$ & $\mathrm{C}$ & & \\
\hline $4 \mathrm{E}$ & $\begin{array}{l}\text { Probablemente de } \\
\text { Solor }\end{array}$ & sin datos de tumba & 7789 & $\mathrm{~F}$ & $\mathrm{C}$ & & \\
\hline $3 \mathrm{~F}$ & Solor 4 & tumba 759 & 7966 & $\mathrm{~F}$ & $\mathrm{C}$ & & \\
\hline
\end{tabular}




\begin{tabular}{|c|c|c|c|c|c|c|c|}
\hline $3 G$ & Tchapuchayna & túmulo 21 & $\begin{array}{l}\text { Sin número de } \\
\text { registro }\end{array}$ & $\mathrm{F}$ & $\mathrm{C}$ & & \\
\hline $3 \mathrm{H}$ & Tchapuchayna & túmulo 23 & $\begin{array}{l}\text { Sin número de } \\
\text { registro }\end{array}$ & $\mathrm{F}$ & $\mathrm{C}$ & & \\
\hline 3 I & Tchapuchayna & túmulo 28 & $\begin{array}{l}\text { Sin número de } \\
\text { registro }\end{array}$ & $\mathrm{F}$ & C & & \\
\hline $3 \mathrm{~J}$ & Tchapuchayna & túmulo 21 & $\begin{array}{l}\text { Sin número de } \\
\text { registro }\end{array}$ & $\mathrm{F}$ & C & & \\
\hline $3 \mathrm{~K}$ & Tchapuchayna & túmulo 21 & $\begin{array}{l}\text { Sin número de } \\
\text { registro }\end{array}$ & $\mathrm{F}$ & C & & \\
\hline $3 \mathrm{~L}$ & Tchapuchayna & túmulo 21 & $\begin{array}{l}\text { Sin número de } \\
\text { registro }\end{array}$ & $\mathrm{F}$ & C & & \\
\hline $3 \mathrm{M}$ & Tchapuchayna & túmulo 21 & $\begin{array}{l}\text { Sin número de } \\
\text { registro }\end{array}$ & $\mathrm{F}$ & $\mathrm{C}$ & & \\
\hline $3 \mathrm{~N}$ & Tchapuchayna & túmulo 21 & $\begin{array}{l}\text { Sin número de } \\
\text { registro }\end{array}$ & $\mathrm{F}$ & C & & \\
\hline 30 & Tchapuchayna & túmulo 21 & $\begin{array}{l}\text { Sin número de } \\
\text { registro }\end{array}$ & $\mathrm{F}$ & $\mathrm{C}$ & & \\
\hline $3 P$ & Tchapuchayna & túmulo 10 & $\begin{array}{l}\text { Sin número de } \\
\text { registro }\end{array}$ & $\mathrm{F}$ & C & & \\
\hline $3 Q$ & Tchapuchayna & túmulo 10 & $\begin{array}{l}\text { Sin número de } \\
\text { registro }\end{array}$ & $\mathrm{F}$ & C & GA, n'31 & \\
\hline $3 R$ & Tulor Algarrobo & sin datos de tumba & 7449 & $\mathrm{~F}$ & $\mathrm{C}$ & $\mathrm{GB}, \mathrm{n}^{\circ} 38$ & \\
\hline $3 \mathrm{~S}$ & Larache & sin datos de tumba & $\begin{array}{l}\text { Sin número de } \\
\text { registro }\end{array}$ & $\mathrm{F}$ & C & $\mathrm{GB}, \mathrm{n}^{\circ} 33$ & \\
\hline $3 \mathrm{~T}$ & Larache & sin datos de tumba & $\begin{array}{l}\text { Sin número de } \\
\quad \text { registro }\end{array}$ & $\mathrm{F}$ & C & $\mathrm{GC}, \mathrm{n}^{\circ} 32$ & $\mathrm{SN}$ \\
\hline $3 \mathrm{U}$ & Larache & sin datos de tumba & $\begin{array}{l}\text { Sin número de } \\
\text { registro }\end{array}$ & $\mathrm{F}$ & $\mathrm{C}$ & & $\mathrm{CN}$ \\
\hline $3 \mathrm{~V}$ & Solor 3 & tumba 1041 & $\begin{array}{l}\text { Sin número de } \\
\text { registro }\end{array}$ & $\mathrm{F}$ & $\mathrm{C}$ & & \\
\hline $3 \mathrm{~W}$ & Tchapuchayna & túmulo 8 & $\begin{array}{l}\text { Sin número de } \\
\text { registro }\end{array}$ & $\mathrm{F}$ & $\mathrm{C}$ & $\mathrm{GC}, \mathrm{n}^{\circ} 28$ & $\mathrm{CN}$ \\
\hline $3 X$ & Tulor Algarrobo & sin datos de tumba & 7450 & $\mathrm{~F}$ & $\mathrm{C}$ & & \\
\hline $3 Y$ & Tulor Algarrobo & sin datos de tumba & 7451 & $\mathrm{~F}$ & $\mathrm{C}$ & & \\
\hline $3 Z$ & Tulor Algarrobo & sin datos de tumba & 7452 & $\mathrm{~F}$ & $\mathrm{C}$ & & \\
\hline $3 \mathrm{AA}$ & Tulor Pueblo & sin datos de tumba & 7599 & $\mathrm{~F}$ & $\mathrm{C}$ & & \\
\hline $3 \mathrm{AB}$ & Beter & sin datos de tumba & $\begin{array}{l}\text { Sin número de } \\
\text { registro }\end{array}$ & $\mathrm{F}$ & C & & \\
\hline $3 \mathrm{AC}$ & Beter & sin datos de tumba & $\begin{array}{l}\text { Sin número de } \\
\text { registro }\end{array}$ & $\mathrm{F}$ & C & $\mathrm{GA}, \mathrm{n}^{\circ} 44$ & \\
\hline $3 \mathrm{AD}$ & Poconche & sin datos de tumba & 7816 & $\mathrm{~F}$ & $\mathrm{C}$ & & \\
\hline $3 \mathrm{AE}$ & Toconao Oriente & tumba 4393-4394 & 4201 & $\mathrm{~F}$ & C & & $\mathrm{CN}$ \\
\hline $3 \mathrm{AF}$ & Coyo & sin datos de tumba & $\begin{array}{l}\text { Sin número de } \\
\text { registro }\end{array}$ & $\mathrm{F}$ & $\mathrm{L}$ & & \\
\hline $3 \mathrm{AG}$ & Coyo Aldea & recolección superficial & $\begin{array}{l}\text { Sin número de } \\
\text { registro }\end{array}$ & $\mathrm{F}$ & C & $\mathrm{GB}, \mathrm{n}^{\circ} 55$ & \\
\hline
\end{tabular}




\begin{tabular}{|c|c|c|c|c|c|c|c|}
\hline $3 \mathrm{AH}$ & Coyo Aldea & recolección superficial & $\begin{array}{l}\text { Sin número de } \\
\text { registro }\end{array}$ & $\mathrm{F}$ & C & $\mathrm{GA}, \mathrm{n}^{\circ} 56$ & $\mathrm{CN}$ \\
\hline $3 \mathrm{AI}$ & Coyo Aldea & recolección superficial & $\begin{array}{l}\text { Sin número de } \\
\text { registro }\end{array}$ & F & $\mathrm{C}$ & $\mathrm{GA}, \mathrm{n}^{\circ} 57$ & \\
\hline $3 \mathrm{AJ}$ & $\begin{array}{l}\text { Sin datos de } \\
\text { contexto }\end{array}$ & sin datos de tumba & & F & $\mathrm{C}$ & $\mathrm{GC}, \mathrm{n}^{\circ} 46$ & $\mathrm{CN}$ \\
\hline $3 \mathrm{AK}$ & Toconao Oriente & tumba 4665-4669 & $\begin{array}{l}\text { Sin número de } \\
\text { registro }\end{array}$ & F & $\mathrm{C}$ & & $\mathrm{CN}$ \\
\hline - & Toconao Oriente & tumba 4317 & 1005 & $\mathrm{BN}$ & $\mathrm{C}$ & & \\
\hline - & Larache & sin datos de tumba & $\begin{array}{l}\text { Sin número de } \\
\text { registro }\end{array}$ & $\mathrm{BN}$ & $\mathrm{L}$ & & \\
\hline- & Tulan 54 & sin datos de tumba & $\begin{array}{l}\text { Sin número de } \\
\text { registro }\end{array}$ & $\mathrm{F}$ & $\mathrm{C}$ & & \\
\hline - & Toconao Oriente & tumba 4635 & $\begin{array}{l}\text { Sin número de } \\
\text { registro }\end{array}$ & $\mathrm{BN}$ & $\mathrm{C}$ & & \\
\hline
\end{tabular}

Tabla 1. Inventario de pipas registradas y resultados generales de los análisis químicos.

Estado: BN: Buen nivel de integridad y F: Fragmentado. Materialidad: C: Cerámica y L: Lítica

Análisis de FRX: GA) pasta identificable con aquellas usadas en objetos encontrados en los sitios habitacionales de la zona del Alto Loa, GB) pasta identificable con aquellas utilizadas en objetos provenientes de contextos habitacionales y funerarios de la cuenca del SA, y GC) pasta con perfil no identificable, posiblemente no-local, seguidos de n de análisis.

Análisis de CG-EM: CN: nicotina y SN: sin nicotina

cuenca del SA, un $81 \%$ en sitios del oasis de SPA, ubicado al norte del SA, y el resto en el área de Toconao, un oasis menor ubicado al sur del SA, y en Tulan 54, también al sur del SA (ver Figura 1). Los sitios en las áreas de Toconao y de Sequitor (ayllu ubicado en SPA) son los que concentraron la mayor abundancia de pipas en un buen nivel de integridad, 42 y $38 \%$ respectivamente. El resto de las pipas con un buen nivel de integridad se encontraron dispersas en otros sectores de SPA (Quitor, Larache y Tchaputchayna). ${ }^{8}$ Respecto de los fragmentos de pipas se encontraron en mayor abundancia en el sector de Tchaputchayna, 34\%; el resto de los fragmentos en otros sectores del SA (Beter, Tulor, Poconche, Coyo, Larache, Solor, Toconao Oriente y Tulan 54). En cuanto a la asociación de las pipas que pudieron ser contextualizadas con las notas de Le Paige, en 38 de 60 casos, ${ }^{9}$ se contó con la descripción de contextos con ajuares asociados a los entierros de pipas. Se destaca la vinculación con las

8 El contexto específico de cada uno de los ejemplares se detalla en la Tabla 1.

9 Cuatro casos corresponden a otros excavadores (Núñez et al. 2007; Graffam 1995) evidencias bioantropológicas, principalmente con el rango etario correspondiente a individuos adultos en $80 \%$ de los casos. Respecto de la relación contextual con otros artefactos, en todos los casos catastrados las pipas se encontraron asociadas a evidencias cerámicas, y dentro de esto llama la atención el hecho de que se presentaron en cantidad unitaria, en contraste con lo que ocurrió con los característicos botellones de la cerámica sanpedrina y otros contenedores cerámicos, que frecuentemente se presentan de modo más cuantioso. El vínculo de pipas con artefactos de metal parece más bien escaso, ya que solo se dio en $12 \%$ de los ajuares descritos en las notas de Le Paige conteniendo pipas. La relación entre pipas y evidencias de artefactos asociados a parafernalia inhalatoria (tabletas para alucinógenos, espátulas, tubos de insuflación, conchas de caracol de agua dulce o cajitas contenedoras de madera y hueso) se presentó en $38 \%$ de los contextos que se pudieron vincular a tumbas (Gili 2014). Respecto de las pipas recuperadas por otros investigadores, destaca su presencia en contextos no funerarios en el sitio habitacional Coyo Aldea (Graffam 1995) y en Tulán 54 , donde aparecen fragmentos de pipas tubulares y angulares de cerámica negra pulida asociadas a ofrendas y 
desechos de actividades doméstico-rituales posicionadas sobre el entierro de un neonato en una estructura arquitectónica denominada el templete (Núñez et al. 2007).10

Respecto de las piezas catalogadas y los fechados publicados para el SA, la data más temprana para pipas en la zona de estudio sería el hallazgo vinculado a las pipas de Tulán fechado en el rango 2630-2420 AP en la transición del Arcaico al Formativo (Núñez et al. 2006). Luego, de los contextos excavados por Le Paige que cuentan con una datación estarían el de Toconao Oriente (tumba 4263) que se obtuvo fechando mediante termoluminiscencia una pipa que arrojó una data de $1750 \pm 160 \mathrm{AP}, 230$ DC y un artefacto cerámico del contexto de otra pipa (Toconao Oriente - tumba 4383), para el cual se obtuvo una fecha de $1670 \pm 160$ AP, 310 DC (Berenguer et al. 1986). También hay otra fecha, $120 \mathrm{DC}$, publicada por Orellana (1991: 39) que corresponde a la tumba 4646-48 de Toconao Oriente donde también se encontró una pipa. Por último, hay dos fechas que coinciden con las nuevas dataciones de Hubbe et al. (2011) correspondientes a una probable pipa de Sequitor Alambrado (tumba 1060-1068), 422-602 DC para la tumba 1062 y 256-544 DC para la tumba 1068. Estas últimas fechas ampliarían la práctica fumatoria hacia el Período Medio; sin embargo, la pipa de dicho contexto (Figura 2.2 F) es muy diferente en su forma a la norma morfológica que se observa para las pipas de la cuenca del salar. Hasta aquí, se la había documentado como pipa (Tarragó 1989, Llagostera 2001), debido a su forma de Tinvertida, en asociación a la tradición morfológica de pipas del Norte Chico. No obstante, la falta de residuos de hollín en su interior hace pensar que se podría tratar de otro tipo de artefacto. ${ }^{11}$

Respecto de las cronologías, si bien estas fechas indican que se trata de un fenómeno del Período Formativo, faltan más fechados absolutos que se vinculen directamente a los contextos y que permitan tener una certeza de su distribución cronológica. Sobre todo en el escenario actual en el cual nuevos fechados (Hubbe et al. 2011, Stovel 2013) han sugerido modificaciones para la secuencia cronológica establecida para las fases culturales de SPA (Tarragó

10 En la Tabla i se presentan como una sola fila, ya que no se pudo acceder a ellas para tener un dato cuantitativo.

11 Podría corresponder a un instrumento musical, tal como es el caso con los silbatos acodados del Norte Chico, los cuales han sido confundidos con pipas.
1968,1989; Berenguer et al. 1986) ya que, según estas nuevas fechas, varios de los sitios revisados en este catastro presentan ocupaciones que abarcan más de un período cronológico (p.e. Quitor 5, Quitor 6 en Hubbe et al. 2011).

\section{Análisis morfológico de las pipas del SA y del NOA}

El material relevado demuestra que en el SA se usaron pipas cerámicas principalmente de forma acodada, con hornillo y tubo y, en general, de grandes dimensiones, llegando a tener una longitud total promedio de 36,9 cm (rango: 15,7-63,1 cm; varianza: 15,8 cm), y el hornillo con una altura promedio de 6,8 cm (rango: 3,5-12,6 $\mathrm{cm}$; varianza: $5,6 \mathrm{~cm}$ ) y un diámetro promedio de 4,5 $\mathrm{cm}$ (rango: 2,2-7,4 cm; varianza: 1,9 cm). ${ }^{12}$ El hornillo está dispuesto de modo vertical sobre dos apoyos cónicos y tiene forma de campana invertida; la amplitud del diámetro mayor es variable según cada ejemplar (debido a su fragilidad, esta sección frecuentemente se encuentra fragmentada). El tubo es cilíndrico y la boquilla remata en un pronunciado labio evertido en ángulo recto. A pesar de dichas similitudes, cada ejemplar presenta variantes tanto en el tamaño de las partes como en el acabado (cocción oxidante o reductora y alisado o pulido) (Gili 2014).

Una revisión exploratoria de antecedentes de pipas publicadas para el NOA permitió conocer la distribución de los hallazgos publicados de ejemplares de este sector (ver Figura 1), ${ }^{13}$ los cuales pudimos agrupar de acuerdo a cualidades determinadas por la forma, los motivos decorativos, la técnica de decoración, la embocadura y el hornillo. Con ello, de modo exploratorio pudimos generar una clasificación que nos permite ver similitudes y diferencias con las pipas del SA, y así contrastar los antecedentes que señalan que las pipas del SA provienen del NOA. En la Tabla 2 se presenta esta aproximación preliminar de la cual podemos observar que existen formas: i) acodadas y tubulares (A, B, C, D, E, F, G, I); ii) con motivos figurativos antropo y zoomorfos $(\mathrm{A}, \mathrm{C}, \mathrm{H})$; iii) orientados hacia el consumidor ( $F$ ), hacia el punto

12 Calculado sobre la base de las dimensiones de las partes de las pipas que estaban completas, ver Tabla 1.

13 Las referencias del reporte de cada uno de estos sitios aparecen en la descripción de la Figura 1. 
Francisca Gili, Javier Echeverría, Emily Stovel, Michael Deibel y Hermann M. Niemeyer

\begin{tabular}{|c|c|c|c|c|c|c|c|}
\hline & & Forma & Motivo & $\begin{array}{l}\text { Técnica de } \\
\text { decoración }\end{array}$ & Embocadura & Hornillo & Sitios \\
\hline A & $\sqrt{0}$ & Acodada & $\begin{array}{l}\text { Figurativo } \\
\text { antropozoomorfo, } \\
\text { con extremidades, } \\
\text { direccionado hacia } \\
\text { punto observado } \\
\text { por el consumidor }\end{array}$ & Modelada & Redondeada & $\begin{array}{c}\text { Tronco cónico } \\
\text { modelado, } \\
\text { con apoyos } \\
\text { levemente } \\
\text { insinuados. }\end{array}$ & $\begin{array}{c}\text { Moralito - NOA } \\
\text { (Yacobaccio 2012), Palpalá } \\
\text { 10- NOA (Fernández et } \\
\text { al. 1999) }\end{array}$ \\
\hline B & & $\begin{array}{l}\text { Acodada, en } \\
\text { algunos casos } \\
\text { con un ángulo } \\
\text { menor a } 90^{\circ}\end{array}$ & Geométricos & $\begin{array}{c}\text { Incisa, } \\
\text { pintura } \\
\text { lineal o sin } \\
\text { decoración }\end{array}$ & Redondeada & $\begin{array}{l}\text { Campanuliforme } \\
\text { invertido }\end{array}$ & $\begin{array}{c}\text { La Ciénaga - NOA } \\
\text { (Fernández et al. 1999) }\end{array}$ \\
\hline $\mathrm{C}$ & & Acodada & $\begin{array}{c}\text { Figurativo } \\
\text { zoomorfo, con } \\
\text { hocico prominente, } \\
\text { direccionado hacia } \\
\text { punto observado } \\
\text { por el consumidor }\end{array}$ & $\begin{array}{l}\text { Modelada e } \\
\text { inciso }\end{array}$ & Redondeada & $\begin{array}{l}\text { Campanuliforme } \\
\text { invertido con } \\
\text { apoyos }\end{array}$ & $\begin{array}{l}\text { Laguna Blanca- NOA } \\
\text { (Fernández et al. 1999), El } \\
\text { Cardonal*, Valle del Cajón, } \\
\text { Puerta de Belén-NOA } \\
\text { (Bugliani et al. 2010) } \\
{ }^{*} \text { La del Cardonal } \\
\text { presenta un apéndice } \\
\text { figurativo zoomorfo en el } \\
\text { tubo que la diferencia de } \\
\text { esta morfologia. }\end{array}$ \\
\hline $\mathrm{D}$ & & Acodada & Geométricos & Incisa & Redondeada & $\begin{array}{c}\text { Campanuliforme } \\
\text { invertido con } / \text { sin } \\
\text { apoyos }\end{array}$ & $\begin{array}{c}\text { Cerro el Dique, Rodeo } \\
\text { Grande - NOA } \\
\text { (Fernández et al. 1999) }\end{array}$ \\
\hline $\mathrm{E}$ & & Acodada & $\begin{array}{l}\text { Abstracción } \\
\text { zoomorfa }\end{array}$ & $\begin{array}{l}\text { Modelado e } \\
\text { inciso }\end{array}$ & Redondeada & $\begin{array}{l}\text { Campanuliforme } \\
\text { invertido/ } \\
\text { troncocónico liso } \\
\text { con apoyos }\end{array}$ & $\begin{array}{l}\text { Campo Colorado -NOA } \\
\text { (Gollán y Gordillo 1993) }\end{array}$ \\
\hline $\mathrm{F}$ & 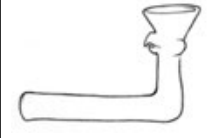 & Acodada & $\begin{array}{c}\text { Figurativos } \\
\text { antropo-zoomorfos } \\
\text { direccionados hacia } \\
\text { el consumidor. }\end{array}$ & Modelado & Redondeada & $\begin{array}{c}\text { Campanuliforme } \\
\text { invertido sobre } \\
\text { base tubular } \\
\text { recta }\end{array}$ & $\begin{array}{c}\text { Rodeo Grande-NOA, } \\
\text { La Aguada (Fernández et } \\
\text { al. 1999) }\end{array}$ \\
\hline G & d & Tubular & - & - & - & - & $\begin{array}{c}\text { San Salvador, } \\
\text { Huachichocana-NOA, } \\
\text { Incacueva-NOA } \\
\text { (Fernandez Distel 1980) }\end{array}$ \\
\hline $\mathrm{H}$ & & $\begin{array}{c}\text { Acodada, } \\
\text { probablemente } \\
\text { articulada. Se } \\
\text { presenta en la } \\
\text { ilustración solo } \\
\text { el hornillo. }\end{array}$ & $\begin{array}{c}\text { Figurativo zoo- } \\
\text { antropomorfos, } \\
\text { varias caras } \\
\text { (dos o cuatro) } \\
\text { direccionada hacia } \\
\text { dos o cuatro puntos } \\
\text { equidistantes }\end{array}$ & Modelado & $\begin{array}{c}\text { No han sido } \\
\text { registradas } \\
\text { piezas } \\
\text { completas, } \\
\text { por lo tanto } \\
\text { desconocemos la } \\
\text { forma del tubo. }\end{array}$ & $\begin{array}{l}\text { Campanuliforme } \\
\text { invertido }\end{array}$ & $\begin{array}{c}\text { La Ciénaga -NOA } \\
\text { (Fernández et al. 1999) }\end{array}$ \\
\hline I & & Acodada & $\begin{array}{l}\text { Abstracción } \\
\text { zoomorfa }\end{array}$ & Modelado & $\begin{array}{l}\text { Labio evertido } \\
\text { recto }\end{array}$ & $\begin{array}{l}\text { Campanuliforme } \\
\text { invertido con } \\
\text { apoyos }\end{array}$ & $\begin{array}{l}\text { Toconao Oriente, Sequitor } \\
\text { Alambrado Oriental, } \\
\text { Sequitor Alambrado } \\
\text { Acequia, Quitor 6, Solor } 3, \\
\text { Larache, (Gili 2014) }\end{array}$ \\
\hline
\end{tabular}

Dibujos: F. Gili

Tabla 2. Formas de pipas del NOA y SA; dibujos hechos a partir de fotografías publicadas y colecciones. 


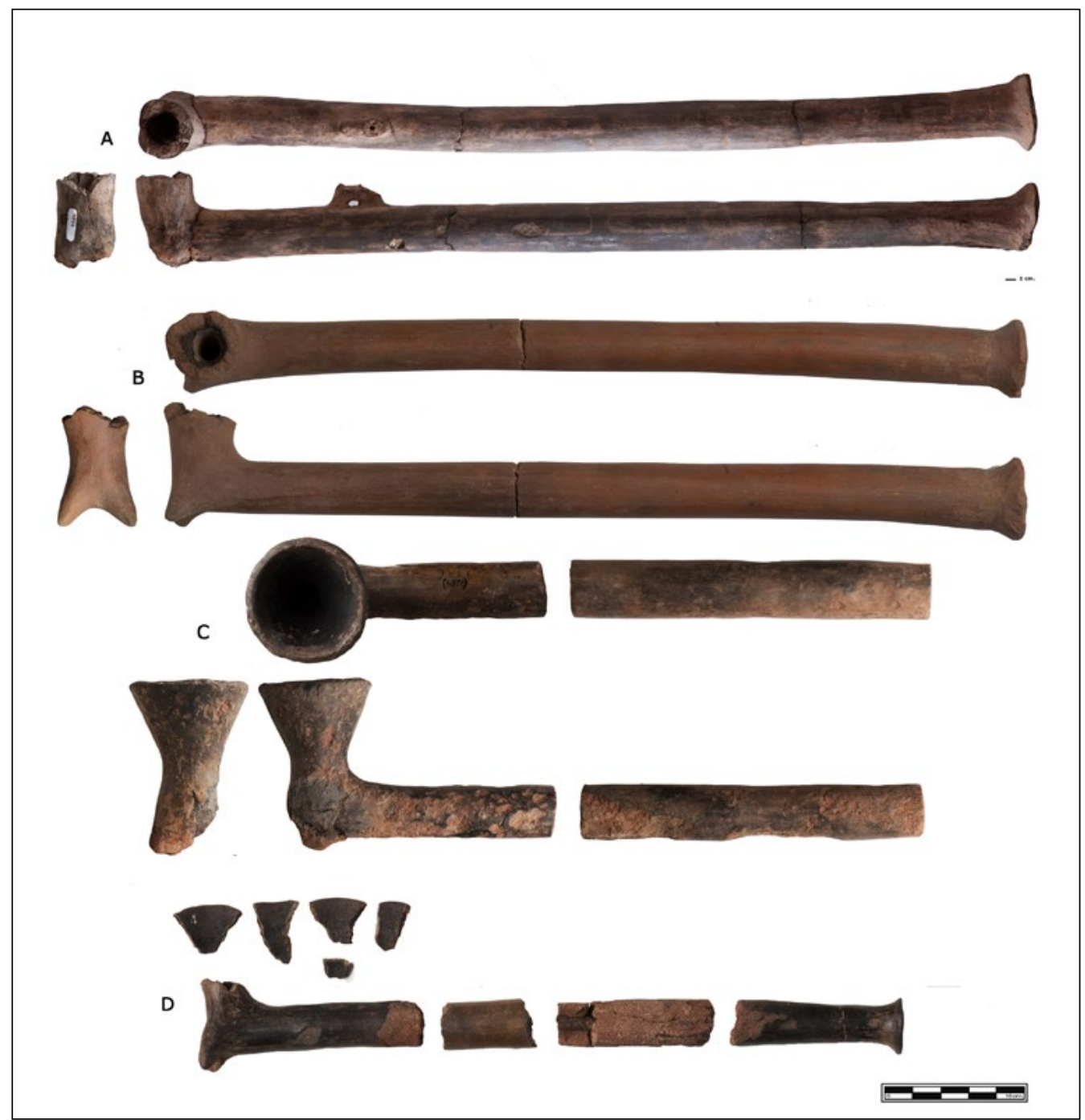

Figura 2.1 Lámina con pipas con un buen nivel de integridad pertenecientes al ayllu de Quitor.

observado por el consumidor (A, C, E, I) y en ambas direcciones (H); iv) con representaciones zoomorfas abstractas (E, I), y v) con motivos geométricos (D). En general, para los hallazgos del NOA, pudimos observar en esta clasificación preliminar de pipas que la forma de la embocadura es redondeada (A, B, C, D, E) y los hornillos son campaniformes invertidos $(B$, C, D, E, F, H) y troncocónicos (A), y presentan en algunos casos insinuación de dos apoyos cónicos bajo el hornillo (A, C, D , E). Estos análisis exploratorios muestran a las pipas del NOA con una variedad de formas que no ocurren en el SA; de hecho, las pipas del SA son semejantes solo en algunas cualidades a las pipas del NOA. Las pipas del SA se distinguen entonces por dos cualidades que definen una norma general de fabricación: la abstracción del motivo asociado al hornillo, que incluye dos apoyos que remiten a los pies de un ser antropo o zoomorfo ambiguo, y la embocadura con un labio evertido recto (I).

\section{Análisis de pastas en pipas de la región occidental del área circumpuneña}

El análisis de componentes principales (Figura 5) captó $90 \%$ de la variación química en una muestra que incluye las pipas y promedios de vasijas del SA y del Alto Loa. 


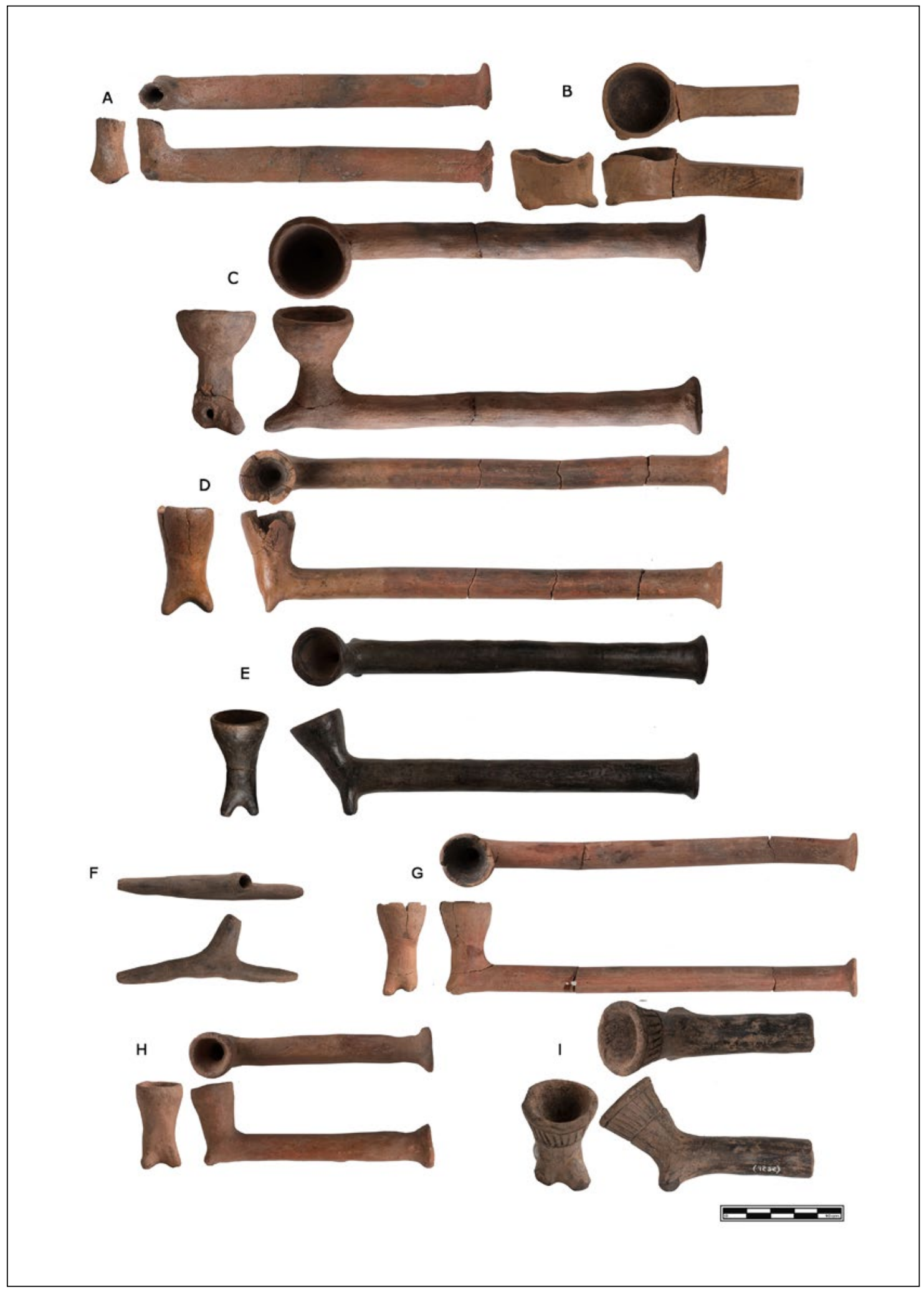

Figura 2.2 Lámina con pipas con un buen nivel de integridad pertenecientes al ayllu de Sequitor. 


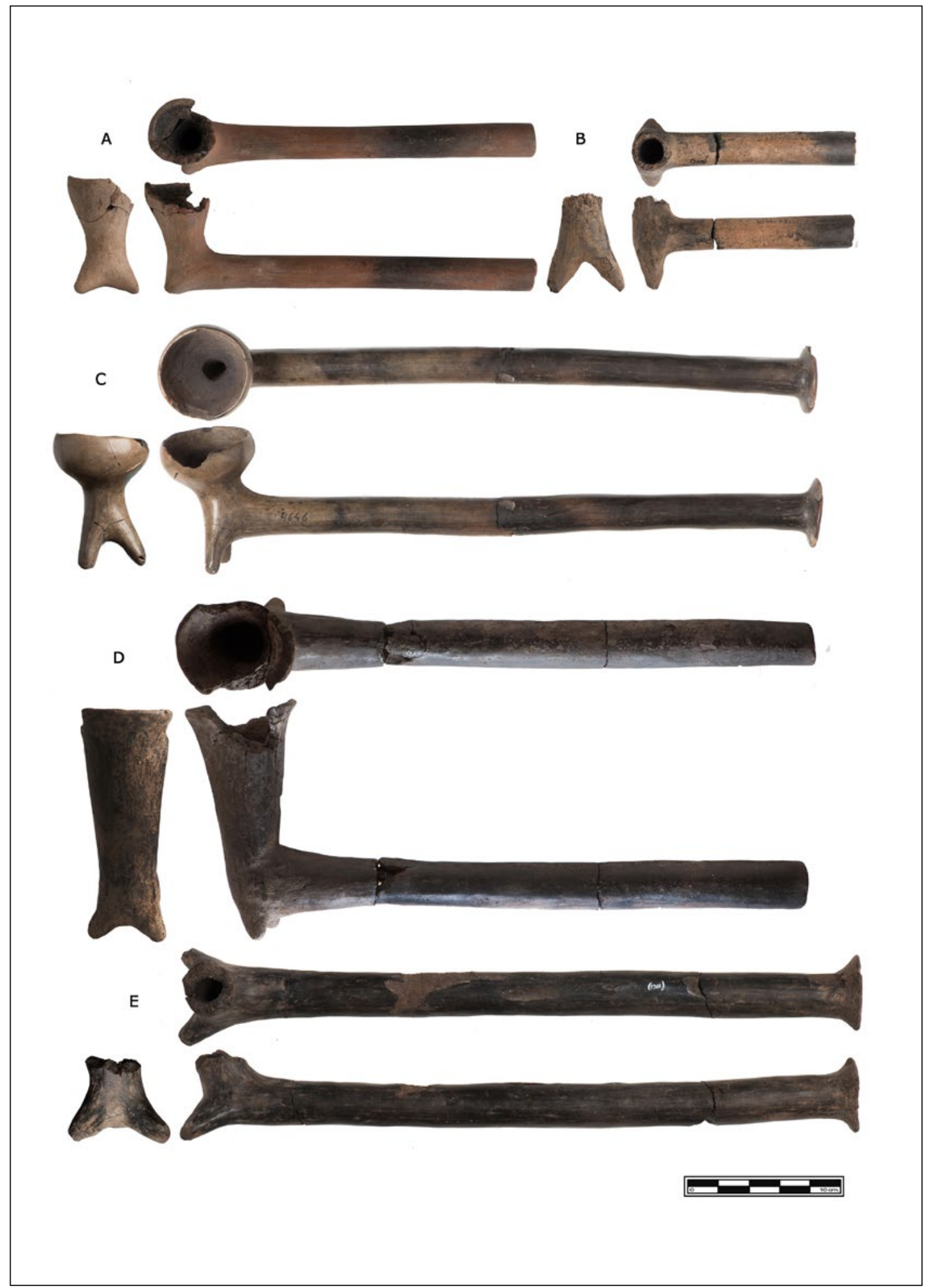

Figura 2.3 Lámina con pipas con un buen nivel de integridad pertenecientes al ayllu de Toconao. 
Tal como fue descrito anteriormente, se compararon los perfiles químicos de las pipas con promedios para vasijas del Período Medio (SP-NP) y del Intermedio Tardío (SP-AIQ, SP-DUP, AL-AIQ, AL-DUP), de contextos funerarios (SP-Burial), y de regiones específicas (SP y $\mathrm{AL}$ ). Los promedios fueron dados por combinaciones de valores para muestras y demostraron que la mayor diferencia entre las mismas tiene que ver más bien con su lugar de producción (es decir, entre las comunidades de SPA y el Alto Loa) que con su lugar de consumo (casa vs. tumba) o período de manufactura (el Período Medio vs. el Intermedio Tardío). Los agrupamientos identificados con el análisis se definieron con solo cinco elementos ( $\mathrm{Fe}, \mathrm{Ti}, \mathrm{Zr}, \mathrm{Rb}$ y $\mathrm{Sr}$ ) y fueron dibujados con elipses de confianza de 95\%. Casi toda la muestra de pipas cayó dentro de tres grupos: A) pasta identificable con aquellas utilizadas en objetos provenientes de contextos habitacionales y funerarios de la cuenca del SA, B) pasta identificable con aquellas usadas en objetos encontrados en los sitios habitacionales de la zona del Alto Loa, y C) pasta con perfil no identificable, posiblemente no-local, o por lo menos sin referencia local identificada hasta el momento. Los ejes de diferenciación entre los grupos se consolidaron entre cantidades relativas de rubidio, estroncio y circonio (y este último en combinación con el hierro y el titanio). En un trabajo anterior (Stovel et al. 2013), se observó que en comparación con pastas del Alto Loa, las pastas de SPA están enriquecidas con

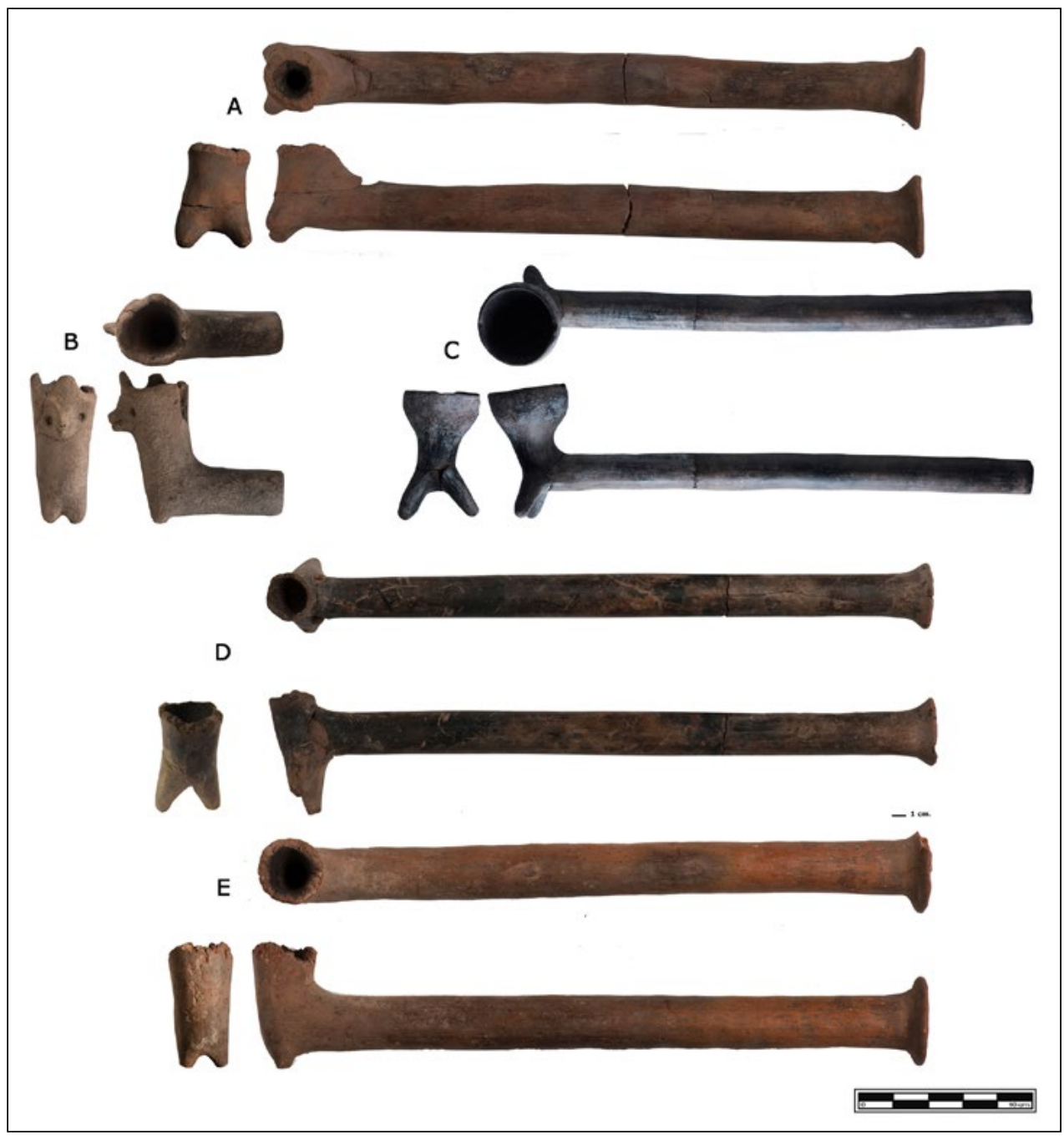

Figura 2.4 Lámina con pipas con un buen nivel de integridad pertenecientes a diversos sectores. 


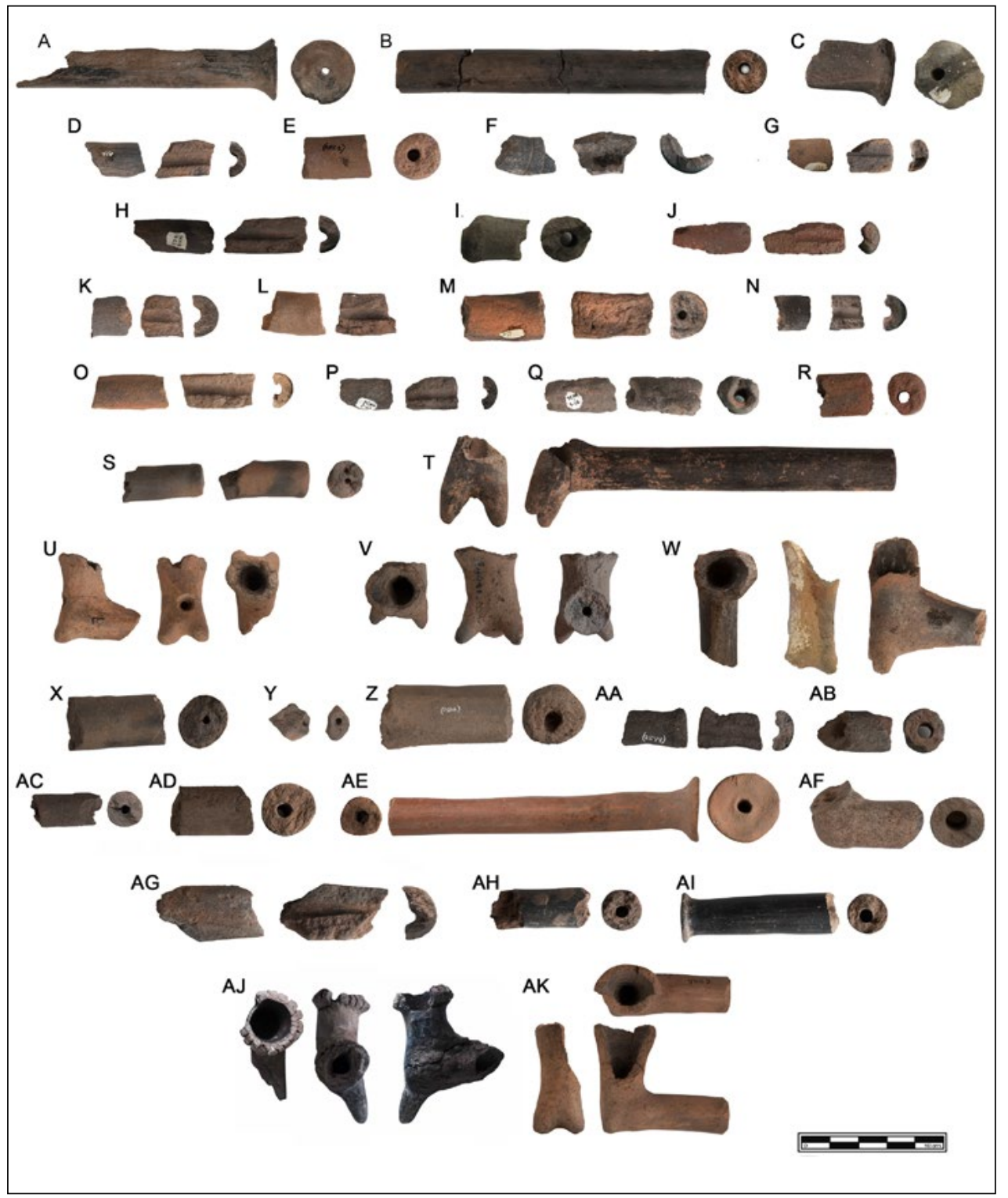

Figura 3. Lámina con fragmentos de pipas pertenecientes al Salar de Atacama.

rubidio. Aquí se pudo confirmar que las pastas del Alto Loa están relativamente enriquecidas con estroncio y circonio-hierro-titanio.

Es importante notar la presencia de un promedio de muestras hechas de arcilla local de SPA (local clay) en el tercer grupo. Las tres muestras (fragmentos de vasijas) analizadas para ese grupo fueron elaboradas con pastas locales extraídas de las orillas del río San Pedro al norte por un alfarero actual. El hecho de que haya un grupo de pipas coincidente con "local clay" (aunque el grupo se ve bastante disperso) sugirió la existencia de una receta o fuente de arcilla adicional y posiblemente local. Este grupo puede representar una receta alfarera local desconocida, que fue utilizada para fabricar pipas o una que fue constituida por elementos diferentes a los que se encontró en vasijas cerámicas producidas localmente. Al mismo tiempo, no se ha identificado la fuente de las materias primas usadas para las vasijas encontradas en tumbas y basurales de SPA. Para explorar con mayor profundidad 


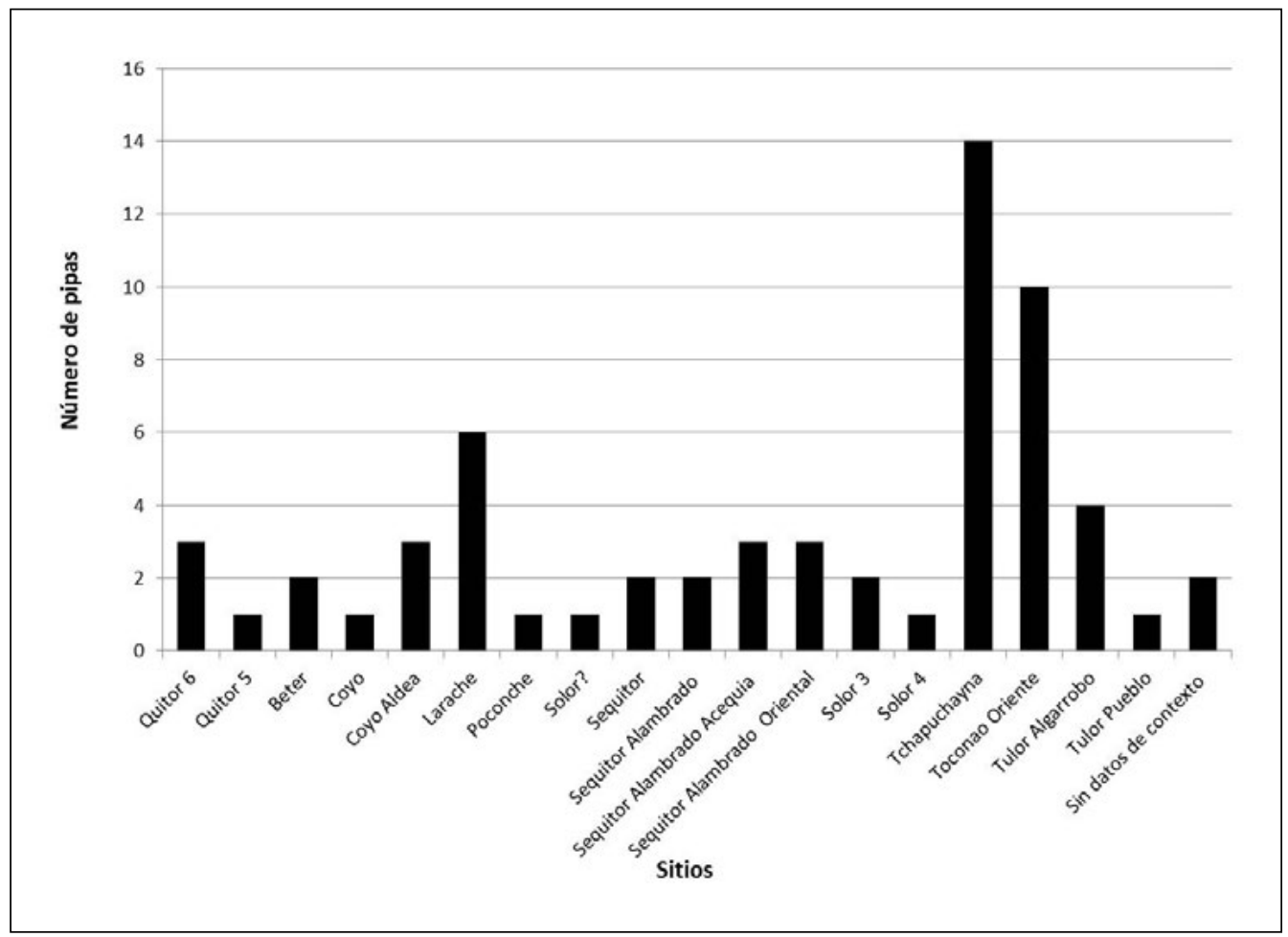

Figura 4. Distribución de pipas por sitio.

estas preguntas sería necesario complementar el trabajo realizado con otros análisis, sobre todo de varias arcillas de fuentes locales y cercanas y los cambios elementales provocados por el proceso de cocción. Los resultados presentados aquí refuerzan la hipótesis que las pipas de la colección del IIAM de SPA se produjeron en la zona (incluyendo el Loa Superior), o por lo menos para dos tercios de la muestra, con las mismas materias/recetas con las cuales los alfareros prehispánicos produjeron sus vasijas con fines domésticos y mortuorios.

\section{Análisis químico de residuos en pipas del SA}

Los análisis químicos por CG-EM de las pipas de SPA en la modalidad barrido completo de iones (BCI) en ambos extractos, clorofórmicos y metanólicos, no mostraron indicios de las moléculas diagnósticas para las especies Anadenanthera sp. y Nicotiana sp. reportadas como usadas en las prácticas fumatorias al nivel regional, i.e., $N, N$-dimetiltriptamina (DMT), 5-metoxi- $N, N$,-dimetiltriptamina (5-MeO-DMT), 5-hidroxi- $N, N$-dimetiltriptamina (5-OH-DMT) y ni- cotina. Estos cromatogramas mostraron, sin embargo, otras moléculas presentes en todas las pipas (Figura 6): i) ésteres metílicos de ácidos grasos, principalmente derivados del ácido palmítico (hexadecanoico), ácido esteárico (octadecanoico) y ácido elaídico [(E)-octadec9 -enoico], ii) esteroides de origen vegetal y animal tales como $\beta$-sitoesterol, colesterol y sus derivados; iii) $n$-alcanos de cadena larga tales como $n$-eicosano; iv) $n$-alcoholes derivados de ácidos grasos de cadena larga, y v) aldehídos derivados de ácidos grasos de cadena larga. Estos compuestos corresponden a una combinación de sustancias de origen vegetal y animal y no son asociables a ninguna especie en particular, ya que son de ocurrencia frecuente en distintas fuentes naturales.

Cuando se utilizó el instrumento en la modalidad de monitoreo selectivo de iones (MSI), de mayor sensibilidad, y buscando iones con relaciones masa/carga $(\mathrm{m} / \mathrm{z})$ e intensidades relativas correspondientes a los alcaloides anteriormente mencionados, se pudo demostrar la presencia de cantidades traza de nicotina en los extractos metanólicos del 68\% del total de pipas muestreadas (Tabla 1). 


\section{• Discusión y CONClusiones}

La pesquisa de las pipas en los depósitos del IIAM permitió dar con un importante corpus de este tipo de artefacto. Se pudieron conocer datos de los tipos de contextos en los que se encontraron los artefactos y también las piezas con las cuales estaban vinculadas; esto permitió destacar el valor informativo que poseen antiguas colecciones que, a pesar de no pertenecer a contextos de excavación sistemática, aportan datos importantes para conocer prácticas del pasado.
Se ha señalado para la zona del SA que el uso de plantas con cualidades visionarias comenzó con el acto de fumar en pipas y luego fue cambiando a la tradición de la inhalación mediante tubos y tabletas (Llagostera 1996; Torres 1998-1999). Ya en 1915 Max Uhle describía: "la curiosa costumbre de tomar rapé por medio de tubos puede haberse derivado de fumar cigarros o la de fumar tabaco en pipas" (Uhle 1915: 115); esta idea es apoyada por Tarragó (1977) y Berenguer y Dauelsberg (1989). Sin embargo, tras reevaluar el tema de los fechados, mediante la comparación de las tumbas registradas y las nuevas dataciones reportadas

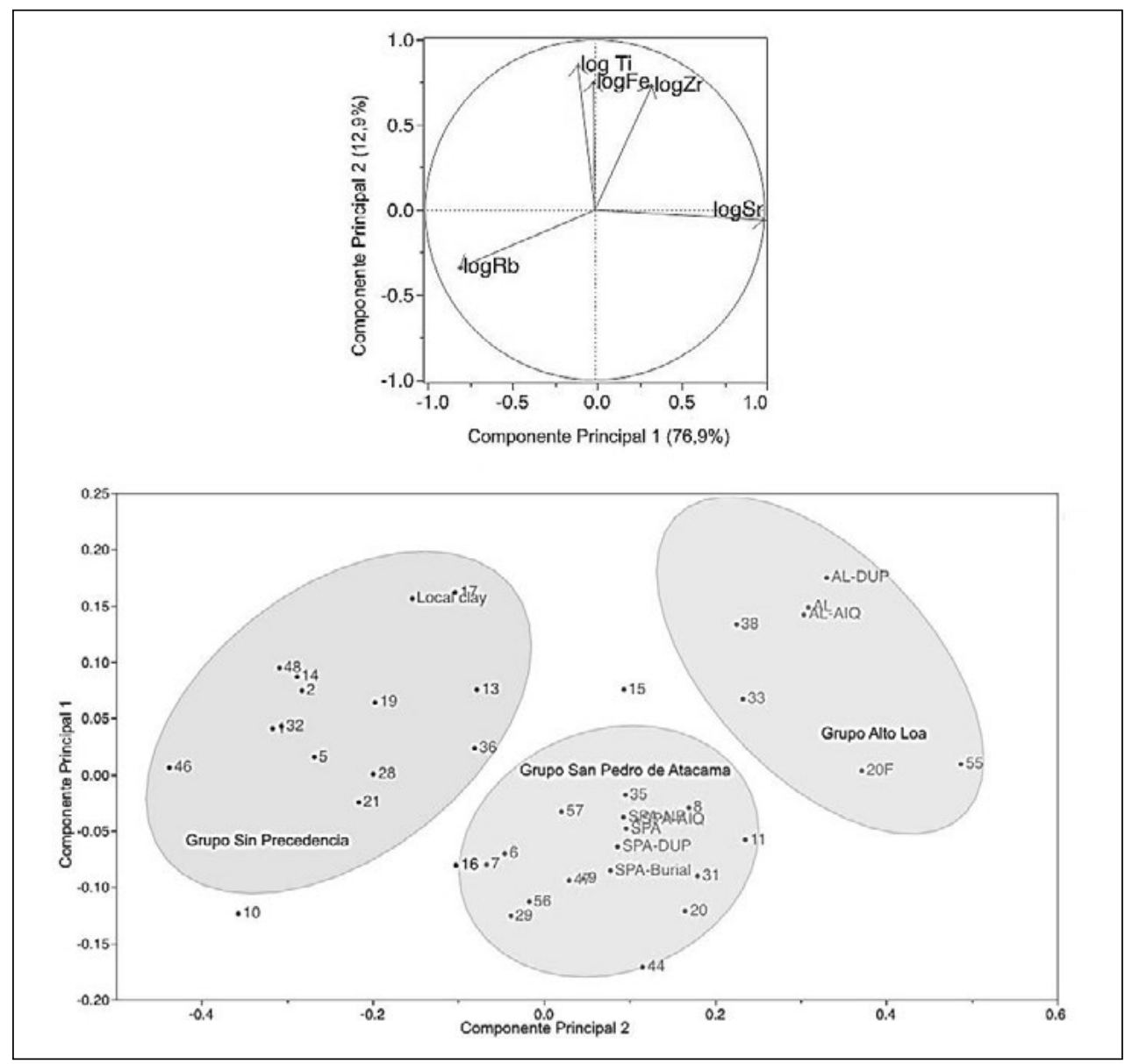

Figura 5. Análisis de componentes principales de la composición de las pastas de las pipas estudiadas (numeradas en el gráfico inferior, conforme al número de pipa designado en el proyecto). Los grupos identificados en el gráfico inferior se distribuyen y se definen según las relaciones entre los elementos del gráfico superior. El primer componente principal captura $3 / 4$ de la variabilidad en la muestra según las cantidades inversas de Rb y Sr. El segundo componente principal, que captura casi 13\% más de la variación, se encuentra en las diferencias entre los valores de Fe/Ti y Zr y los de Rb y Sr. AL-DUP: promedio de valores para vasijas tipo Dupont del Alto Loa/AL-AIQ: promedio de valores para vasijas tipo Aiquina del Alto Loa/ AL: promedio de valores para vasijas del Alto Loa/ SPA-NP: promedio de valores para vasijas tipo Negro Pulido de San Pedro de Atacama/ SPA-DUP: promedio de valores para vasijas tipo Dupont de San Pedro/ SPA-AIQ: promedio de valores para vasijas tipo Aiquina de San Pedro/ SPA: promedio de valores para vasijas de San Pedro/ SPA-Burial: promedio de valores para vasijas de ajuar de San Pedro. /Local clay: arcilla local. 


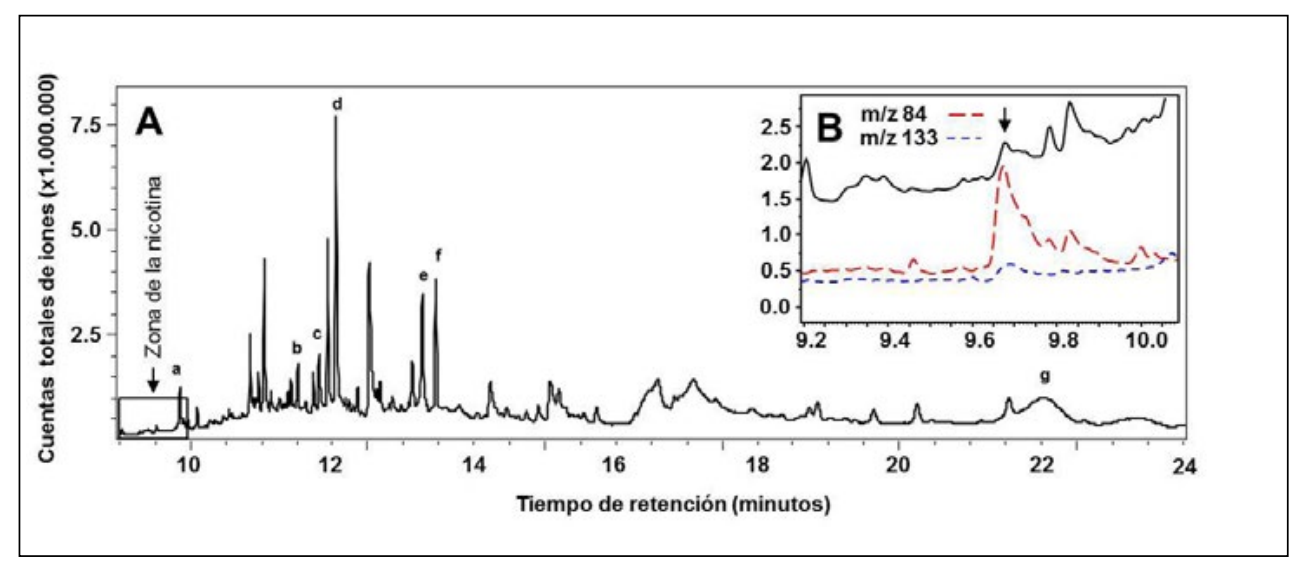

Figura 6. Análisis por cromatografía de gases acoplada a espectrometría de masas del extracto metanólico obtenido a partir del residuo de la pipa Coyo Aldea (Figura $3 \mathrm{AI}$ ): A) Cromatograma en el modo de barrido completo de la muestra donde se indican los compuestos identificados: a) metiléster del ácido láurico, b) metiléster del ácido n-pentadecanoico, c) n-pentadecanol, d) metiléster del ácido palmítico, e) metiléster del ácido elaídico, f) metiléster del ácido esteárico, y g) $\beta$-sitosterol; B) Cromatograma en el modo de monitorización selectiva de iones en la zona de aparición de nicotina (flecha); se usaron los dos iones mayoritarios en el espectro de masas de la nicotina, con $\mathrm{m} / \mathrm{z} 84$ y 133 (se muestra también una curva correspondiente a la suma total de iones).

para el SA (Hubbe et al. 2011, Stovel 2013, Richardin et al. 2015), en el presente trabajo nos damos cuenta de la necesidad de generar nuevas dataciones que permitan contextualizar cronológicamente el uso de estos artefactos. Si bien comentamos que las fases cronológicas propuestas para el SA están siendo reevaluadas, creemos que las pipas pueden ser un elemento que aporte a este conocimiento, así como lo han sido en el caso de los restos bioantropológicos, más todavía teniendo en cuenta las pipas que contienen en su interior residuos de hollín que pueden ser datados mediante $\mathrm{C}^{14}$-AEM.

Por otra parte, es interesante considerar las adaptaciones que experimentan las pipas en el SA; el problema fue abordado desde la morfología, la composición de pastas y el contenido de sus residuos. Algunas de las pipas encontradas en la cuenca del SA presentan ciertas semejanzas morfológicas y estilísticas con aquellas elaboradas en cerámica durante el Período Formativo en el NOA (Tarragó 1989; Westfall 1993-1994: 124; Torres 1998-1999: 53-54; Llagostera 2001: 104); sin embargo, la mayor parte de ellas presenta cualidades morfológicas con características que permitirían distinguirlas de aquellas de otros sectores. Las pipas del NOA, aunque de gran variabilidad morfológica, presentan en varios casos una antropo-zoomorfización de su hornillo que tiende a ser figurativa; en contraposición, las pipas del
SA muestran una abstracción de los elementos que sugieren la antropo-zoomorfización, ${ }^{14}$ a tal punto que solo se pueden observar los dos apoyos cónicos bajo el hornillo que representarían los pies o patas de estos seres "ambiguos". Por otra parte, las pipas del NOA muestran tubos con embocadura redondeada, en tanto en las del SA el tubo termina generalmente en un labio evertido perpendicularmente al eje del tubo; más aún, en las pipas en que el labio evertido parecería ausente se nota una huella de fractura en el tubo que aparece desgastado por reutilización (Figura 7).

Respecto a la densidad numérica de los hallazgos de pipas en el área Atacameña podemos ver que la cantidad de ejemplares presentes en el SA supera con creces el número de pipas que se han encontrado en otras zonas del área. Casi la totalidad de los casos recopilados fuera del SA, corresponden a hallazgos más bien aislados y poco frecuentes, además de ser claramente vinculables por comparación morfológica con piezas encontradas en otras zonas del área circumpuneña. Esto permite suponer que las pipas encontradas en estas últimas áreas corresponden a bienes de intercambio que estu-

14 Con la excepción de dos pipas figurativas, una del sitio Tchapuchayna - tumba 3821 y una del sitio Toconao - tumba 4635 (Llagostera 2001: 117, fig. 21). 

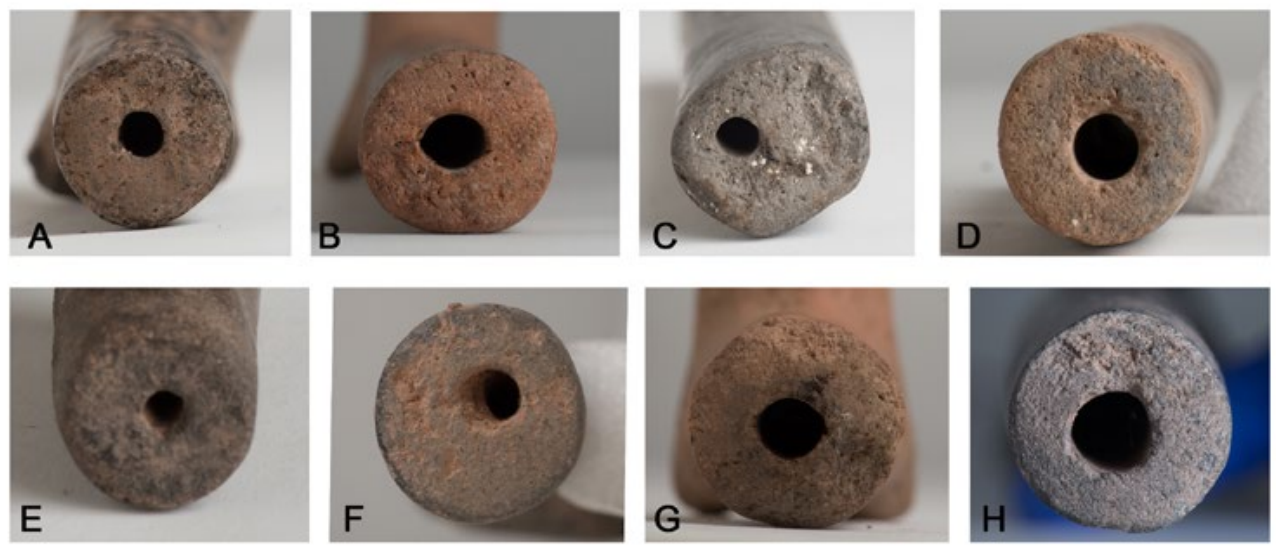

Figura 7. Zonas proximales de pipas fragmentadas con desgaste por uso: A) Sequitor Alambrado Oriental tumba 1075/1080; B) Toconao Oriente tumba 4263; C) Toconao Oriente tumba 4383; D) Quitor 6 tumba 2796-2799; E) Tchaputchayna tumba 3821; F) Larache sin datos de tumba; G) Toconao Oriente tumba 4665-4669; H) Larache sin datos de tumba.

vieron presentes en el constante flujo que caracterizó a estas culturas.

Los análisis químicos de pastas cerámicas y el posterior análisis de componentes principales de las composiciones elementales obtenidas, permitieron identificar preliminarmente un conjunto de pipas que utilizaron pastas semejantes a aquellas identificadas en objetos de contextos funerarios y domésticos de la cuenca del SA y otro conjunto de la zona aledaña del Alto Loa. Este hecho, junto al hallazgo de una pipa con pasta cerámica sin cocción encontrada en el sitio Socaire 22 por el arqueólogo Patricio Núñez (Gili y Villagrán 2011), y junto también con los resultados del estudio morfológico que define una norma para las pipas del SA, apoyan la hipótesis de un desarrollo local de manufactura de pipas en el SA, a diferencia de planteamientos anteriores (Tarragó 1989; Westfall 1993-1994; Torres 1998-1999; Llagostera 2001; Llagostera 2015) según los cuales las pipas de la cuenca del SA habrían tenido un origen foráneo. Por otra parte, es destacable el hecho de que las pastas atribuidas al Alto Loa correspondan solo a fragmentos de tubos, lo que podría estar relacionado con la fragilidad de estos objetos y su ruptura durante el traslado desde estas zonas aledañas.
Tenemos evidencia de la presencia de restos de cerámica del Alto Loa en contextos de SPA y la ausencia de restos que se trasladaron en la dirección opuesta (Alden et al. 2006; Stovel et al. 2013). Es posible que tal como las vasijas del Intermedio Tardío, las pipas producidas en el Alto Loa fueran incorporadas a contextos funerarios de SPA. Al mismo tiempo, es importante destacar que las comunidades del Alto Loa produjeron cerámica muy semejante a las del SA desde el Período Formativo hasta el Período Tardío (Sinclaire et al. 1997; Uribe 1997, 2002). Todo lo anterior nos presenta un problema cronológico adicional. Si se produjeron estilos cerámicos muy semejantes durante una gran parte del período agro-alfarero, además de estilos y estructuras muy similares en los textiles durante el Período Intermedio Tardío de las comunidades de SPA, Quillagua, El Salvador, y el Alto Loa (Adán y Uribe 2005; Agüero et al. 1997; González y Westfall 2008; Pimentel et al. 2007; Uribe 2009). ¿La producción de pipas semejantes en las comunidades de SPA y el Alto Loa refleja tal vez un momento temprano en la cohesión material que se ve en la zona Atacameña del Intermedio Tardío? Entender mejor el uso de estos objetos requiere un análisis profundo de sus elementos de producción y sus contextos de consumo. 
El tercer grupo de pipas, cuyas pastas no se pudieron vincular a los perfiles de las bases de datos existentes, sugiere dos posibilidades: i) que son piezas foráneas y por ello no son coincidentes con la base de datos de las pipas del SA y Alto Loa; o ii) que son elaboradas localmente con preparaciones arcillosas hechas con recetas o materias distintas a la alfarería encontrada y ya analizada en las casas y tumbas de SPA. Sin embargo, el hecho de que un grupo coincida con materiales de cerámica utilizados en SPA y en el Alto Loa sugiere que en ambos casos los artesanos eligieron producir pipas con las mismas recetas y arcillas empleadas para fabricar otros objetos y caen dentro de una producción generalizada alfarera, en contraste con una producción especializada y exclusiva que requeriría materiales o recetas especiales y/o ajenas en cada caso. En virtud del carácter relativo de los resultados de FRX, los cuales fueron utilizados para aproximarnos de modo exploratorio a la composición de las pastas, resaltamos que es importante a futuro corroborar estos resultados con análisis de estilo, petrografía, u otros métodos químicos, por ejemplo, el análisis por activación de neutrones.

Los compuestos orgánicos detectados en los residuos carbonizados de las pipas analizadas constituyen una matriz compleja conformada por compuestos no alcaloidales y alcaloidales. Los primeros pueden ser atribuidos tanto a fuentes vegetales como animales. La presencia mayoritaria de ésteres metílicos de ácidos grasos de cadena lineal saturada es coherente con el uso de grasas de naturaleza animal, probablemente en relación con su alta combustibilidad, poder calórico y capacidad para catalizar la combustión de otras sustancias. Como único compuesto alcaloidal se encontró nicotina. La baja proporción de pipas cuyos residuos contienen nicotina es consistente con los resultados negativos para alcaloides en pipas reportados por Torres (1998-1999) y con la aparición de nicotina en cantidades trazas, cercanas al límite de detección del método analítico. Diversos factores pueden explicar la baja cantidad de nicotina encontrada: i) que la especie de Nicotiana consumida haya sido parte de una mezcla de especies consumidas de forma conjunta y que por lo tanto el alcaloide haya estado originalmente diluido en una matriz vegetal compleja; ii) que se haya consumido una especie del género
Nicotiana u otra especie con una concentración particularmente baja del alcaloide (ver por ejemplo, Espinoza et al. 2012); iii) que la nicotina se haya degradado químicamente producto de la acción del tiempo y las condiciones ambientales, y que iv) debido a las grandes dimensiones de los hornillos y a la utilización de sustancias particularmente calóricas, la combustión del material vegetal haya alcanzado altas temperaturas, y por consiguiente se haya producido una mayor volatilización y la consecuente pérdida de estos alcaloides desde la matriz. Es interesante destacar que los resultados de los residuos que dieron análisis positivo de nicotina son coherentes con aquellos provenientes del análisis químico de cabellos de momias del SA que demostró el consumo de nicotina entre la población que habitó en la cuenca del salar (Echeverría y Niemeyer 2013).

En pipas provenientes del NOA, la complejidad de sus residuos ha sido demostrada a través de estudios arqueobotánicos que muestran la presencia de microrrestos de especies tales como cebil (Anadenanthera colubrina var. cebil), tabaco (Nicotiana sp.), coca (Erythroxylum coca), cedrón (Aloysa citriodora), yerba mate (Ilex sp.), maíz (Zea mays) y algodón (Gossyypium sp.) (Capparelli et al. 2006; Andreoni et al. 2012; Martin 2012) y de estudios químicos que han señalado la presencia de alcaloides triptamínicos (Fernández Distel 1980; Rosso y Spano 2005-2006; Bugliani et al. 2010) y de ácidos grasos diversos (Pazzarelli 2011). Estos estudios muestran el uso de especies vegetales con alcaloides, probablemente asociado a sus propiedades analgésicas y a su capacidad de modificar los estados de conciencia (Janiger y Dobkin 1973, 1976; Elferink 1983; Wilbert 1991), y también de otras especies, que puede guardar relación con la cadena operativa del uso de las pipas (limpieza y/o encendido), con ser especies que pueden tener una eficacia simbólica en el contexto cultural de uso, por sus cualidades aromáticas y farmacológicas, o su capacidad de promover la combustión y producir humo. A esta última capacidad podría también ser asociada la presencia de grasas animales; sin embargo, éstas también pueden aparecer en materiales arqueológicos como consecuencia de la manipulación inadecuada de las piezas durante y con posterioridad a la excavación (Belmar et al. 2014). 
La presencia de triptaminas y de microrrestos de cebil en las pipas del NOA está sin duda relacionada con la cercanía y relativa disponibilidad de esta especie en los bosques de las Yungas y sus zonas aledañas, en contraste con la inexistencia de cebil al lado occidental de la cordillera, en el SA y en lugares cercanos (Gili et al. 2016). Por otra parte, la presencia de microrrestos de Nicotiana en pipas del NOA y de nicotina en pipas del SA estaría relacionada con la distribución de este género vegetal en ambas regiones geográficas (Goodspeed 1954; Carrasco et al. 2015).

La diversidad de compuestos de origen vegetal que se encontraron en los residuos de las pipas del SA muestra la inclusión de múltiples insumos en el material utilizado, y sugiere una amplitud de efectos deseados. Por otra parte, el gran tamaño de las pipas del SA en comparación con el de las pipas del norte semiárido y centro-sur de Chile, ${ }^{15}$ sugiere un uso colectivo (como propone Llagostera 2001), y un diseño orientado a producir grandes cantidades de humo que logren ocupar un amplio ambiente. Se podría hipotetizar que el labio evertido de las pipas del SA pudo haber tenido algún rol en la práctica de insuflar aire a través de las pipas, en estas prácticas. Estas características son consistentes con la posibilidad de que las pipas fuesen, en el SA, un elemento que pudiera servir tanto para fumar como para producir sahumerios. El uso de plantas para sahumar no solo ha sido documentado y descrito etnográficamente en diversas culturas alrededor del mundo (Pennacchio et al. 2010), sino que ha sido señalado como una tradición muy difundida en Sudamérica (Wilbert 1991), en particular en la zona andina de Bolivia (Mariscotti 1978; Girault 1987; Macía et al. 2005), en el altiplano de Argentina (García y Rolandi de Perrot 2000; Molina y Romero 2008) y en el norte de Chile (Aldunate et al. 1983), específicamente en la cuenca del SA (Villagrán y Castro 2003). De hecho, la hipótesis del probable uso como incensario de las pipas del área circumpuneña ya fue propuesto hace algunas décadas en el NOA (Debenedetti 1931; González 1961-64). Además, destaca y llama la atención que en la etnografía de la zona atacameña se identifiquen los coberos

15 Cuyas dimensiones son menores; por ejemplo en el caso del sitio "La Granja" el largo desde el hornillo a la boquilla varía entre $9 \mathrm{~cm}$ y $1,5 \mathrm{~cm}$ (Planella et al. 2016).
(Varela 2002), artefactos vinculados al sahumado, sin que exista a la fecha un correlato en la arqueología local. En resumen, deberíamos repensar la idea que el tubo sirvió solo para inhalar humo y considerar que a lo mejor sirvió para el proceso de soplar, o como tiraje y así también contribuir en la producción de humo para llenar un ambiente. En este escenario, considerar las conceptualizaciones vernáculas en torno al sahumerio y al humo para interpretar el uso y forma de las pipas abre puertas interesantes para comprender estos objetos que presentan atributos morfológicos ambiguos y de transformación. Como señalan Alberti y Marshall (2009), el entendimiento de la condición material está determinado por las prácticas en las que se utilizan los artefactos. En este sentido, Kusch (2001: 185) se refiere a las pipas: "este sistema conceptual se orienta hacia la representación de comportamientos ambivalentes, expresados en torno a la combinación y/o yuxtaposición de atributos pertenecientes a distintas especies y, al parecer, vinculado al tema de la transformación". Investigaciones etnográficas describen el concepto de la "koa", "koya" o "wirakoa" como "lo que se transforma en otra cosa" (Villagrán et al. 1998: 109), y a su vez también designa una categoría vernácula para referirse a arbustos resinosos y aromáticos cuyo humo es ofrendado a las divinidades en los pagos (Villagrán y Castro 2003). Es así como la forma puede sugerir prácticas, contextos y usos que ante la luz de estos resultados abren nuevas perspectivas para seguir investigando las pipas y su función social.

\section{$*$ Conclusión}

En conclusión, las pipas aparecen en el registro arqueológico hace unos 4.000 años en el NOA y hace solo unos 2.500 años en la vertiente opuesta de los Andes. El período de su uso en el SA, si bien ha sido propuesto con anterioridad para el Período Formativo, necesita ser reevaluado en vista de los nuevos fechados que han sido reportados para esta localidad. Mientras las pipas del NOA muestran variedad morfológica, las del SA tienen una norma en su morfología determinada por la simplificación del motivo asociado al hornillo y la embocadura con un labio evertido recto. Vemos en las pipas del SA una forma que mantiene una norma, i.e. pipa acodada con tubo y hornillo de gran tamaño y hornillo con dos apoyos inferiores, que traspasó las fronteras de 
la cordillera de los Andes y fue adquiriendo variantes locales en cuanto a: i) particularidades de sus atributos morfológicos, las cuales pueden estar vinculadas a variantes en la ideología y por tanto en la configuración de la estética local; ii) la composición de su cerámica, lo cual se relaciona con los procesos tecnológicos de producción y iii) las sustancias combustionadas, que se puede asociar con la disponibilidad de sustancias vegetales y la búsqueda de especies y/o combinaciones de especies con atributos similares tanto físico-químicos - por su capacidad de producir humo tras la combustión-, como por su capacidad de ser eficaces terapéutica y/o simbólicamente en las prácticas realizadas. El tamaño del hornillo y el labio evertido sugieren la posibilidad de que la pipa haya sido usada tanto para fumar como en sahumerios. Esta hipótesis abre una nueva perspectiva de investigación sobre los residuos carbonizados de las pipas basadas en la búsqueda de elementos botánicos y/o químicos asociables a la utilización de plantas resinosas eficientes en la producción de humo y también de plantas con efectos terapéuticos.

\section{* Agradecimientos}

Francisca Gili agradece a Helena Horta y a Javier Echeverría por haber guiado la investigación de posgrado que se expone en el presente artículo; a Manuel Constantino Torres por su ayuda y excelente disposición y generosidad; al Programa de Postgrado de Antropología de la Universidad Católica del Norte por la beca MECESUP, que permitió su participación en dicho programa, dentro del cual se realizó esta investigación; a Nicolás Aguayo por las fotografías de los artefactos mostrados en el artículo, y al IIAM y su personal por resguardar las colecciones recuperadas por Gustavo Le Paige y por prestar las facilidades para trabajar con ellas. Javier Echeverría agradece el financiamiento otorgado por el proyecto postdoctoral FONDECYT $3130327 \mathrm{y} \mathrm{el}$ proyecto FONDECYT 1160849. Finalmente, agradecemos a los evaluadores anónimos por sus generosos y valiosos comentarios y sugerencias. 


\section{$*$ Referencias citadas}

ADÁN, L., y S. URBINA. 2007. Arquitectura formativa en San Pedro de Atacama. Estudios atacameños 29: 7-30.

ADÁN, L. y M. URIBE. 2005. El dominio inca en la localidad de Caspana: Un acercamiento al pensamiento político andino (río Loa, norte de Chile). Estudios atacameños 29: 41-66.

AGUERRE, A., A. FERNÁNDEZ DISTEL y C. ASCHERO. 1973. Hallazgo de un sitio cerámico en la quebrada de Inca Cueva (Provincia de Jujuy). Relaciones de la Sociedad Argentina de Antropología 7: 197-235.

AGÜERO, C., M. URIBE, P. AYALA y B. CASES. 1997. Variabilidad textil durante el Período Intermedio Tardío en el Valle de Quillagua: una aproximación de la etnicidad. Estudios Atacameños 14:263-290.

ALBERTI, B. y Y. MARSHALL. 2009. Animating archaeology: local theories and conceptually open-ended methodologies. Cambridge Archaeological Journal 19:344-356.

ALBORNOZ, X. 2015. Plantas Sagradas en grupos del Norte semiárido, un contexto Diaguita-Inca. Tesis para optar al título de Arqueólogo, Universidad Internacional SEK.

ALDEN, J., L. MINC y T. LYNCH, 2006. Identifying the sources of Inka period ceramics from northern Chile: Results of a neutron activation study. Journal of Archaeological Science 33: 575-594.

ALDUNATE, C. 1989. Estadio alfarero en el sur de Chile. En Prehistoria. Serie Culturas de Chile desde sus orígenes hasta los albores de la conquista, J. Hidalgo, V. Schiappacasse, H. Niemeyer, C. Aldunate y I. Solimano (Eds.), pp. 329-348. Editorial Andrés Bello, Santiago de Chile.

ALDUNATE, C., J. ARMESTO, V. CASTRO y C. VILLAGRÁN. 1983. Ethnobotany of pre-Altiplanic community in the Andes of northern Chile. Economic Botany 37: 120-135.

ALDUNATE, C., J. BERENGUER, V. CASTRO, L. CORNEJO, J. L. MARTÍNEZ y C. SINCLAIRE. 1986. Cronología y asentamiento en la Región del Loa Superior. Dirección de Investigación y Bibliotecas de la Universidad de Chile, Santiago.

ALDUNATE, C., 1991. Arqueología en el Pukara de Turi. Boletín del Museo Regional de LaAraucanía 4: 61-78.
ANDREONI, D. F., R. C. SPANO y V. LEMA. 2012. Nota sobre evidencias de uso de plantas en el sitio Soria 2 a partir del análisis microscópico del contenido de pipas. Arqueología 18: 235-243.

ASCHERO, C. y H. YACOBACCIO. 1998/1999. 20 años después: Inca Cueva 7 reinterpretado. Cuadernos del Instituto Nacional de Antropología y Pensamiento Latinoamericano 18: 7-18.

BALLESTER, B. y F. GALLARDO. 2011 Prehistoric and Historic Networks on the Atacama Desert Coast (Northern Chile). Antiquity 85: 875-889.

BAXTER, M. J. 1995. Standardization and transformation in principal component analysis, with applications to archaeometry. Applied Statistics 44: 513-527.

BAXTER, M. J., y C. M. JACKSON. 2001. Variable selection in artefact compositional studies. Archaeometry 43: 253-268.

BELMAR, C., D. MUNITA, S. ALFARO, X. ALBORNOZ, C. CARRASCO, J. ECHEVERRÍA, R. MERA, L. ADÁN, L. QUIROZ, H. M. NIEMEYERy M. T. PLANELLA. 2016. Cachimbas y kitras: Un acercamiento a las prácticas fumatorias de grupos alfareros del Centro-Sur de Chile. Ms. en preparación.

BELMAR, C. A., L. D. QUIROZ, H. M. NIEMEYER, M. T. PLANELla, X. ALbORNOZ, F. MENESES, S. K. ALFARO, C. CARRASCO, K. COLLAO-ALVARADO y J. ECHEVERRÍA. 2014. Condiciones previas para el uso de marcadores arqueobotánicos y químicos en estudios arqueológicos y arqueométricos sobre complejos fumatorios: una propuesta de protocolo para manipulación del objeto y toma de muestras. Intersecciones en $A n$ tropología 15: 497-501.

BERENGUER, J. y N. ACEVEDO. 2015. Tubos de hueso de ave como implementos chamánicos en el Desierto de Atacama, Siglos XI-XV. Boletín del Museo Chileno de Arte Precolombino 20: 51-72.

BERENGUER, J. y P. DAUELSBERG. 1989. El Norte Grande en la órbita de Tiwanaku (400 a 1200 d.C.). En Prehistoria: Desde sus Orígenes Hasta los Albores de la Conquista, J. Hidalgo, V. Schiappacasse, H. Niemeyer, C. Aldunate e I. Solimano (Eds.), pp. 129180, Editorial Andrés Bello, Santiago de Chile.

BERENGUER, J., A. DEZA, A. ROMÁN y A. LLAGOSTERA, 1986. La secuencia de Myriam Tarragó para San Pedro de Atacama: Un test por termoluminiscencia. Revista Chilena de Antropología 5: 17-54. 
BUGLIANI, M. F., C. M. CALO y M. C. SCATTOLIN. 2010. Fumando en la cocina: Determinación de contenidos por técnicas físico químicas en dos pipas cerámicas del sitio Cardonal. En La arqueometría en Argentina y Latinoamérica, pp. 231-236. Universidad Nacional de Córdoba, Córdoba.

BUGLIANI, M. F. y L. PEREYRA-DOMINGORENA. 2012. Una aproximación estilístico-tecnológica a la cerámica polícroma 'vaquerías' del noroeste argentino. Estudios Atacameños 43: 121-138.

CAPPARELLI, A., M. L. POCHETTINO, D. ANDREONI y R. D. ITURRIZA. 2006. Differences between written and archaeological record: The case of plant micro remains recovered at a Northwestern Argentinean Pipe. Proceedings of the IVth International Congress of Ethnobotany (ICEB 2005): 397-406.

CARRASCO C., J. ECHEVERRÍA, B. BALLESTER y H. M. NIEMEYER. 2015. De pipas y sustancias: costumbres fumatorias durante el formativo en el litoral del desierto de Atacama (norte de Chile). Latin American Antiquity 26: 143-161.

CASTRO, V., C. ALDUNATE y J. BERENGUER. 1984. Orígenes altiplánicos de la fase Toconce. Estudios Atacameños 7: 209-235.

CORNELY, F. 1956 Cultura Diaguita Chilena y Cultura de El Molle. Editorial del Pacífico, Santiago.

DE SMET, P. A. G. M. 1985. Ritual enemas and snuffs in the Americas. LatinAmerican Studies 33, CEDLA, Amsterdam, Nederland.

DEBENEDETTI, S. 1931. L'ancienne civilisation des Barreales. Ars Americana, vol. 2. Paris.

ECHEVERRÍA, J. y H. M. NIEMEYER. 2013. Nicotine in the hair of mummies from San Pedro de Atacama (Northern Chile). Journal of Archaeological Science 40: 3561-3568.

ECHEVERRÍA, J., M. T. PLANELLA y H. M. NIEMEYER. 2014. Nicotine in residues of smoking pipes and other artifacts of the smoking complex from an Early Ceramic period archaeological site in central Chile. Journal of Archaeological Science 44: 55-60.

ELFERNIK, J. G. R. 1983.The Narcotic and hallucinogenic use of tobacco in pre-columbian Central Andes. Journal of Ethnopharmacology 7 : 111-122.

ESPINOZA, J., J. ECHEVERRÍA, A. URZÚA y H. M. NIEMEYER, 2012. Withanolid amine and nicotine from Dunalia spinosa (Solanaceae). Boletín Latinoamericano y del Caribe de Plantas Medicinales y Aromáticas 11: 278-284.
FALABELLA, F., M. T. PLANELLA y B. TAGLE. 2001. Pipes and smoking tradition in the prehispanic societies of the early ceramic period of the central region of Chile. Eleusis 5: 137-151.

FERNÁNDEZ, A. M., M. G. RAVIÑA y B. BALESTA . 1999. Las pipas precolombinas del norte argentino. Academia Nacional de la Historia, vol. 3 de Corpus Antiquitatum Americanensium: Argentina.

FERNÁNDEZ DISTEL, A. 1980. Hallazgo de pipas en complejos precerámicos del borde de la Puna Jujeña (República Argentina) y el empleo de alucinógenos por parte de las mismas culturas. Estudios Arqueológicos 5: 55-75.

FRANKEL, D. y J. M. WEBB. 2012. Pottery production and distribution in prehistoric Bronze Age Cyprus. An application of pXRF analysis. Journal of Archaeological Science 39: 1380-1387.

FURST, P. T. [1972] 1990. Flesh of the Gods: The Ritual Use of Hallucinogens. Revised edition. Illinois: Waveland Press.

GARCÍA, S. y D. S. ROLANDI DE PERROT. 2000. Relatos y ritual referidos a la Pachamama en Antofagasta de la Sierra, Puna meridional argentina. Relaciones de la Sociedad Argentina de Antropología 25: 7-24.

GILI, F., F. ESPINOSA, A. VILLAGRÁN. 2009. Diseño de una estrategia analítica para la conservación de información asociada: el caso de dos complejos alucinógenos. Conserva 13: 41-59.

GILI, F. y A. VILLAGRÁN. 2011. El caso de estudio de una pipa del sitio Socaire 22, San Pedro de Atacama, Chile. En II Congreso Latinoamericano de Arqueometría L. Vettef, R. Vega-Centeno, P. Olivera y S. Penick (Eds.): 443-452. Lima, Perú.

GILI, F. 2014. La práctica fumatoria en la cuenca del salar de Atacama durante el periodo Formativo. Tesis para optar al grado de Magíster en Antropología con mención en Arqueología. Programa de Postgrado en Antropología, Universidad Católica del Norte Universidad de Tarapacá.

GILI, F., X. ALBORNOZ, J. ECHEVERRÍA, M. GARCÍA, C. CARRASCO, F. MENESES y H. NIEMEYER. 2016. Vilca, Encuentro de miradas: herramientas para su pesquisa en contextos arqueológicos del área centro sur andina. Chungara, Ms aceptado y publicado en línea.

GIRAULT, L. 1987. Kallawaya: Curanderos itinerantes de los Andes. En Kallawaya: Curanderos itinerantes de los andes. Quipus.

GOODALE, N., D. G. BAILEY y G. T. JONES. 2012. XRF: A study of inter-instrument performance. Journal of Archaeological Science 39(4): 875-883. 
GOODSPEED, T. H. 1954. The Genus Nicotiana. Origins, Relationships and Evolution of its Species in the Light of their Distribution, Morphology and Cytogenetics. Chronica Botanica Company, Waltham.

GONZÁLEZ, A. R. 1961-64. La Cultura de La Aguada del noroeste argentino. Revista del Instituto de Antropología, Facultad de Filosofía y Humanidades, TII y III, Córdoba.

GONZÁLEZ, C. y C. WESTFALL. 2008. Atacameños en El Salvador: Nuevas apreciaciones sobre un fardo funerario del Cementerio Las Turquesas. Estudios Atacameños 35: 49-73.

GORDON, A. 1985. Huimpil, un cementerio agro-alfarero temprano. CUHSO II: 19-70.

GRAFFAM, G. 1995. Informe preliminar. Aldea de Coyo, San Pedro de Atacama. Informe no publicado depositado en la biblioteca del Instituto de Investigaciones Arqueológicas y Museo Gustavo Le Paige, San Pedro de Atacama.

HORTA, H. 2014. Lo propio y lo ajeno: definición del estilo san pedro en la parafernalia alucinógena de los oasis del salar de Atacama. Chungara 46: 559-583.

HUBBE, M., M. OVIEDO, y C. TORRES-ROUFF. 2011. El estado de conservación de la colección osteológica Gustavo Le Paige y su contextualización cronológica. Estudios Atacameños 41: 29-44.

HUNT, A. M. W. y R. J. SPEAKMAN. 2015. Portable XRF analysis of archaeological sediments and ceramics. Journal of Archaeological Science 53: 626-638.

JANIGER, O. y M. D. DOBKIN DE RIOS. 1973. Suggestive hallucinogenic properties of tobacco. Medical Anthropology Newsletter 4: 6-11.

JANIGER, O., y M. D. DOBKIN DE RIOS. 1976. Nicotiana an hallucinogen? Economic Botany 30: 295-297.

JOHNSON, J. 2014. Accurate measurements of low Z elements in sediments and archaeological ceramics using portable X-Ray fluorescence (PXRF). Journal of Archaeological Method and Theory 21: 563-588.

KUSCH, F. 2001. Formas alucinadas: Las pipas del período de integración regional. Segundas Jornadas de Arte y Arqueología: Museo Chileno de Arte Precolombino. 180-192.

LATCHAM, R. 1909. El comercio precolombino en Chile y otros países de América. Anales de la Universidad de Chile 125: 241-284.

LATCHAM, R. 1940. Observaciones acerca de la cultura "El Molle". Boletín del Museo Nacional de Historia Natural 18: 17-21.
LE PAIGE, G. 1955-1975. Notas de registro de excavaciones y salvatajes arqueológicos. Documento interno digitalizado. IAA.

LLAGOSTERA, A. 1996. San Pedro de Atacama: nodo de complementariedad reticular. En Integración Surandina: Cinco siglos después. Estudios y debates regionales andinos, X. Albó, M. Aratia, J. Hidalgo, L. Núñez, A. Llagostera, M. Remy y B. Revesz (Eds.), Centro de Estudios Regionales Andinos Bartolomé de las Casas, Cusco. 91: 17-42.

LLAGOSTERA, A. 2001. Archaeology of hallucinogens in San Pedro de Atacama (North Chile). Eleusis 5: 101-121.

LLAGOSTERA, A. 2015. Albores del psicotropismo en San Pedro de Atacama. Pipas v/s Tabletas. Chungara. Revista de Antropología Chilena 47: 489-505.

MACÍA, M. J., E. GARCÍA y P. JAI VIDAURRE. 2005. An ethnobotanical survey of medicinal plants commercialized in the markets of La Paz and El Alto, Bolivia. Journal of Ethnopharmacology 95:337-350.

MARISCOTTI, A. M. 1978. Pachamama Santa Tierra. Contribución al estudio de la religión autóctona en los Andes Centro-Meridionales. Mann, Berlin.

MARTÍN, V. 2012. Informe Final Beca EVC-CIN Convocatoria 2011: "Hacia una comprensión en el uso de enteógenos en las tierras bajas meridionales del NOA: Análisis de microfósiles en pipas de cerámica del sitio Yánimas I (La Cocha, prov. de Tucumán)". Programa Estímulo a las Vocaciones Científicas del Consejo Interuniversitario Nacional. Ms.

MOLINA, A. I. y F. S. ROMERO. 2008. Daño, terapéutica ritual y manipulación de lo sagrado en las medicinas tradicionales del Noroeste Argentino. Ciencias Sociales y Religión/Ciências Sociais e Religião 10: 137-158.

MOSTNY, G. 1952. Una tumba de Chiuchiu. Boletín del Museo Nacional de Historia Natural 26: 1-55.

MOSTNY, G. 1964. Arqueología de Taltal: Epistolario de Augusto Capdeville con Max Uhle y Otros. DIBAM, Fondo Histórico y Bibliográfico José Toribio Medina, Santiago.

NIEMEYER, H., G. CASTILlO y M. CERVELLINO. 1989. Los primeros ceramistas del Norte Chico: Complejo El Molle (o800 d.C.). En Prehistoria. Serie Culturas de Chile Desde sus Orígenes Hasta los Albores de la Conquista, J. Hidalgo, V. Schiappacasse, H. Niemeyer, C. Aldunate y I. Solimano (Eds.). pp. 227-263. Editorial Andrés Bello, Santiago. 
NIEMEYER, H., M. CERVELLINO y G. CASTILLO. 1998. Culturas Prehistóricas de Copiapó. H. Niemeyer y M. Cervellino (Eds.), Museo Regional de Atacama.

NIEMEYER, H. M. 2013. On the provenience of wood used in the manufacture of snuff trays from San Pedro de Atacama (Northern Chile). Journal of Archaeological Science 40:398-404.

NIEMEYER, H. M. y C. AGÜERO. 2015. Dyes used in pre-Hispanic textiles from the Middle and Late Intermediate periods of San Pedro de Atacama (Northern Chile): new insights into patterns of exchange and mobility. Journal of Archaeological Science 57: 14-23.

NIEMEYER, H. M., D. SALAZAR, H. HORTA TRICALLOTIS y F. PEÑA-GÓMEZ. 2015. New insights into the Tiwanaku style of snuff trays from San Pedro de Atacama (northern Chile). Latin American Antiquity 26: 120-137.

NIEMEYER, H. M., V. ZAPATA, P. CANTILLANA, A. MISSENE, J. AGUILERA y A. TORRES. 2013. Computed tomography study of snuff trays from San Pedro de Atacama (Northern Chile). Journal of Archaeological Science 40: 2036-2044.

NÚÑEZ, L., I. CARTAJENA, C. CARRASCO y P. DE SOUZA. 2005. El templete de Tulán y sus relaciones formativas panandinas (Norte de Chile). Boletín del Instituto Francés de Estudios Andinos 34: 299-320.

NÚÑEZ, L., I. CARTAJENA, C. CARRASCO, P. DE SOUZA y M. GROSJEAN. 2006. Emergencia de comunidades pastoralistas formativas en el sureste de la Puna de Atacama. Estudios Atacameños 32: 93-117.

NÚÑEZ, L., P. DE SOUZA, I. CARTAGENA Y C. CARRASCO 2007 Quebrada Tulan: evidencias de interacción circumpuneña durante el Formativo Temprano en el sureste de la Cuenca de Atacama. En C. Aschero (Ed.), Producción y circulación prehispánicas de bienes en el sur andino, pp. 287-304. Editorial Brujas, Córdoba.

ORELLANA, M. 1991. Contextos culturales tempranos de Toconao Oriente. Diálogo Andino 10: 22-46.

PAZZARELLI, F. 2011. Nota: una aproximación a la transformación de recursos en Piedras Blancas (Ambato, Catamarca, siglos X-XI d.C.) desde los análisis químicos. Relaciones de la Sociedad Argentina de Antropología XXXVI: 331-336.

PARDO, O. y J. PIZARRO. 2005. La chicha en el Chile precolombino. Editorial Mare Nostrum, Santiago de Chile.
PENNACCHIO, M., L. JEFFERSON y K. HAVENS. 2010. Uses and Abuses of Plant-Derived Smoke: Its Ethnobotany as Hallucinogen, Perfume, Incense, and Medicine. Oxford University Press.

PÉREZ GOLLÁN, J. A. e I. GORDILLO. 1994. Vilca/Uturuncu. Hacia una arqueología del uso de los alucinógenos en las sociedades prehispánicas de los Andes del Sur. Cuicuilco 1: 99-140.

PIMENTEL, G., I. MONTT, J. BLANCO y A. REYES. 2007. Infraestructura y prácticas de movilidad en una ruta que conectó el altiplano boliviano con San Pedro de Atacama (II Región, Chile). En Producción y circulación prehispánicas de bienes en el sur andino, A. Nielsen, C. Rivolta, V. Seldes, M. Vásquez y P. Mercolli (Eds.), pp. 351-282. Editorial Brujas, Córdoba.

PLANELLA, M. T., C. A. BELMAR, L. D. QUIROZ, F. FALABELLA, S. K. ALFARO, J. ECHEVERRÍA y H. M. NIEMEYER. 2016a. Towards the reconstruction of the ritual expressions of societies of the Early Ceramic Period in Central Chile: Social and cultural contexts associated with the use of smoking pipes. En Perspectives on the Archaeology of Pipes, Tobacco and other Smoke Plants in the Ancient Americas pp. 231-254. Springer International Publishing.

PLANELLA, M. T., C. BELMAR, L. QUIROZ, H. M. NIEMEYER, F. FALABELLA, S. ALFARO, J. ECHEVERRÍA, X. ALBORNOZ, C. CARRASCO y K. COLLAO-ALVARADO. 2016b. Saberes compartidos y particularidades regionales en las prácticas fumatorias de sociedades del Período Alfarero Temprano del norte semiárido, centro y sur de Chile, América del Sur. Ms. en preparación.

PLANELLA, M. T., F. FALABELLA Y B. TAGLE. 2000. Complejo fumatorio del período Alfarero Temprano en Chile central. Contribución Arqueológica 5: 895-909.

PLANELLA, M. T., C. BELMAR, L. QUIROZ y D. ESTÉVEZ. 2012. Propuesta integradora para un estudio del uso de plantas con propiedades psicoactivas en pipas del Período Alfarero Temprano y sus implicancias sociales. Revista de Antropología 25: 93-119.

QUIROZ, D. y M. SÁNCHEZ. 2005. La secuencia Pitrén-El Vergel en Isla Mocha: soluciones de continuidad y distinciones culturales. En: Actas del XVI Congreso Nacional de Arqueología Chilena, pp. 369-378. Editado por el Museo de Historia Natural de Concepción, DIBAM y Sociedad Chilena de Arqueología. Escaparate Ediciones, Concepción, Chile.

REYES, V., L. SANHUEZA y L. ADÁN. 2003-2004. Alfarería doméstica y funeraria de la región del Calafquén. Revista Chilena de Antropología 17: 151-179. 
RICHARDIN, P., C. LAVIER, H. HORTA, V. FIGUEROA, N. LIRA. 2015. Radiocarbon dating of Atacama (Chile) snuff trays: an update on stylistic and chronological correlations. Radiocarbon 57: 1-10.

RIQUELME-TORO, I. y H. M. NIEMEYER. 2015. Tabletas del complejo psicotrópico de San Pedro de Atacama: Nuevas perspectivas desde el análisis anatómico de la madera. En El Horizonte Medio: Nuevos Aportes para el Sur de Perú, Norte de Chile y Bolivia, A. Korpisaari y J. Chacama (Eds.), pp. 281-294. Instituto Francés de Estudios Andinos - Universidad de Tarapacá.

ROSSO C. y R. SPANO. 2005-2006. Evidencias del uso de alucinógenos en pipas halladas en dos sitios tempranos de los Valles Calchaquíes. Arqueología 13: 79-99.

SALAZAR, D., H. M. NIEMEYER, H. HORTA, V. FIGUEROA y G. MANRÍQUEZ. 2014. Interaction, social identity, agency and change during Middle Horizon San Pedro de Atacama (Northern Chile): A multidimensional and interdisciplinary perspective. Journal of Anthropological Archaeology 35: 135-152.

SERRANO. 1934. El uso del tabaco y vegetales narcotizantes entre los indígenas de América. Revista Geográfica Americana 15. Año II, vol. II: 415-425.

SCHULTES, R. E. 1998. Antiquity of the use of New World hallucinogens. The Heffter Review of Psychedelic Research 1: 1-7.

SHACKLEY, M. S. 2011. An introduction to X-Ray fluorescence (XRF) analysis in archaeology. In X-Ray Fluorescence Spectrome$\operatorname{try}(X R F)$ in Geoarchaeology, M. S. Shackley (Ed.) pp. 7-44. New York, NY: Springer New York.

SINCLAIRE, C., M. URIBE, P. AYALA y J. GONZÁLEZ. 1997. La alfarería del Período Formativo en la región del Loa Superior: Sistematización y tipología. Contribución Arqueológica 5: 285-314.

SPEAKMAN, R. J. y M. S. SHACKLEY. 2013. Silo science and portable XRF in archaeology: a response to Frahm. Journal of Archaeological Science 40: 1435-1443.

STOVEL, E. 2013. Prehistoric atacameño ceramic styles and chronology reassessed. Chungara. Revista de Antropología Chilena 45 (3): 371-385.

STOVEL, E. M., W. T. WHITEHEAD, M. A. DEIBEL y M. URIBE. 2013. Relaciones cerámicas y sociales entre San Pedro de Atacama y el Loa Superior durante el Período Intermedio Tardío a través del análisis de fluorescencia de rayos-x portátil. Estudios Atacameños 46: 47-60.
TARRAGÓ, M. 1968. Secuencias culturales de la etapa agroalfarera de San Pedro de Atacama (Chile). Actas y Memorias del $37^{\circ}$ Congreso Internacional de Americanistas, vol. 2, pp. 119-144. Buenos Aires.

TARRAGÓ, M. 1977. Relaciones prehispánicas entre San Pedro de Atacama (norte de Chile) y regiones aledañas: la Quebrada de Humahuaca. Estudios Atacameños 5: 51-64.

TARRAGÓ, M. 1989. Contribución al Conocimiento Arqueológico de las Poblaciones de los Oasis de San Pedro de Atacama en Relación Con los Otros Pueblos Puneños, en Especial, el Sector Septentrional del Valle Calchaquí. Tesis para optar al grado de Doctor en Historia, especialidad Antropología. Universidad de Rosario, Rosario, Argentina.

TARRAGÓ, M. 1996. El Formativo en el noroeste argentino y el alto valle Calchaquí. Revista del Museo de Historia Natural de San Rafael (Mendoza) 23: 103-119.

THOMAS, C., A. BENAVENTE, I. CARTAJENA y G. SERRACINO. 1995. Topater, un cementerio temprano: una aproximación simbólica. Hombre y Desierto 9: 159-170.

THOMAS, C., A. BENAVENTE y C. MASSONE. 1989-1990 Investigaciones arqueológicas de la región del Loa Medio. Revista Chilena de Antropología 8: 53-61.

TORRES, C. 1987. The iconography of the Prehispanic snuff trays from San Pedro de Atacama, Northern Chile. Andean Past 1: 191254.

TORRES, C. 1998-1999. Psychoactive substances in the archaeology of Northern Chile and NW Argentina. Chungara. Revista de Antropología Chilena 30: 49-63.

TORRES, C. 2001. Shamanic inebriants in South America archaeology: Recent investigations. Eleusis 5:3-12.

TORRES, C., D. B. REPKE, K. CHAN, D. MACKENNA, A. LLAGOSTERA y R. E. SCHULTES. 1991. Snuff powders from Pre-Hispanic San Pedro de Atacama: Chemical and contextual analysis. Current Anthropology 32: 640-649.

TORRES, C. y D. REPKE. 2006. Anadenanthera visionary plant of ancient South America. The Haworth Herbal Press, New York.

TORRES-ROUFF, C., G. PIMENTEL y M. UGARTE. 2012. ¿Quiénes viajaban? Investigando la muerte de viajeros post arcaicos en el desierto de Atacama (ca. 800 AC-1536 DC). Estudios Atacameños 43: 167-186. 
TYKOT, R. H., N. M. WHITE y J. P. DU VERNAY. 2013. Advantages and disadvantages of pXRF for archaeological ceramic analysis: Prehistoric pottery distribution and trade in NW Florida. En Archaeological Chemistry VIII, R. A. Armitage YJ. H. Burton (Eds.), pp. 233-244. American Chemical Society, Washington, DC.

UHLE, M. 1915. Los tubos y tabletas de rapé en Chile. Revista Chilena de Historia y Geografía 16: 114-136.

URIBE, M. 1997. La alfarería de Caspana y su relación con la prehistoria tardía de la subárea Circumpuneña. Estudios Atacameños 17: $243-262$.

URIBE, M. 2002. Sobre alfarería, cementerios, fases y procesos durante la prehistoria tardía del desierto de Atacama (800-1600 DC). Estudios Atacameños 22: 7-32.

URIBE, M. 2009. El Período Formativo de Tarapacá y su cerámica: Avances sobre complejidad social en la costa del Norte Grande de Chile (900 aC-80o dC). Estudios Atacameños 37: 5-27.

VARELA G., V. 2002. Enseñanzas de alfareros toconceños: tradición y tecnología en la cerámica. Chungara. Revista de Antropología Chilena 34: 225-252.
VARELA, V., M. URIBE y L. ADÁN, 1991. La cerámica arqueológica del sitio Pukara de Turi: O2-Tu-O02. Boletín del Museo Regional de LaAraucanía 4: 107-121.

VILLAGRÁN, C. y V. CASTRO. 2003. (2012 ult. edición). Ciencia indigena de los Andes del norte de Chile. Editorial Universitaria, Santiago.

VILLAGRÁN, C., V. CASTRO, G. SÁNCHEZ, M. ROMO, C. LATORRE y L. F. HINOJOSA. 1998. Etnobotánica del área del Salar de Atacama (Provincia de El Loa, Región de Antofagasta, Chile). Estudios Atacameños 16: 7-105.

WESTFALL, C. 1993-1994. Pipas prehispánicas de Chile. Discusión en torno a su distribución y contexto. Revista Chilena de Antropología 12: 123-161.

WILBERT, J. 1991. Does pharmacology corroborate the nicotine therapy and practices of South American shamanism. Journal of Ethnopharmacology 32: 179-186.

WILBERT, J. 1987. Tobacco and Shamanism in South America. Yale University Press, New Haven, CT. 